\title{
Sistemas de partículas interagentes dependentes de tipo e aplicações ao estudo de redes de sinalização biológica
}

\author{
Manuel Alejandro González Navarrete
}

\author{
DISSERTAÇÃO APRESENTADA \\ AO \\ Instituto de Matemática e Estatística \\ DA \\ Universidade DE SÃo PAUlo \\ PARA \\ OBTENÇÃO DO TÍTULO \\ $\mathrm{DE}$ \\ Mestre em CiÊnCIAS \\ Programa: Estatística \\ Orientador: Prof. Dr. Eduardo Jordão Neves
}

Durante o desenvolvimento deste trabalho o autor recebeu auxílio financeiro da CNPq

São Paulo, março de 2011 


\section{Sistemas de partículas interagentes dependentes de tipo e aplicações ao estudo de redes de sinalização biológica}

Esta versão definitiva da dissertação contém as correções e alterações sugeridas pela Comissão Julgadora durante a defesa realizada por Manuel Alejandro González Navarrete em 06/05/2011.

Comissão Julgadora:

- Prof. Dr. Eduardo Jordão Neves (orientador) - IME-USP.

- Prof. Dr. Anatoli Iambartsev - IME-USP.

- Profa. Dra. Nancy Lopes Garcia - UNICAMP. 


\section{Agradecimentos}

Primeiramente, gostaria de agradecer aos meus pais, Lelis e Elvira, e a minha família pelo apoio e carinho de sempre. Un gran abrazo a la distancia y muchas gracias por ayudarme a cumplir este sueño.

Agradeço a minha namorada Fernanda pela ajuda nesse tempo juntos, embora tenha sido dificil para nós ficar longe das nossas famílias, com você do meu lado a saudade foi superada.

Ao meu orientador, Prof. Dr. Eduardo Jordão Neves pela paciência, respeito e dedicação. Muito obrigado por ter-me proposto e ensinado sobre esta área de pesquisa.

Aos professores do IME-USP com os quais tive aulas no mestrado, particularmente ao Prof. Dr. Rafael Grisi, o meu primeiro professor no Brasil, obrigado pelos ensinamentos.

Os professores da Universidad de La Frontera, especialmente ao Prof. Dr. Antonio Sanhueza e o Prof. Dr. Hernán Burgos. Além dos professores do Liceo Padre Alberto Hurtado de Loncoche, particularmente à memoria de Ricardo Silva.

Aos amigos que fiz aqui no Brasil: Milton, Gerson e Carlos do quarto 11 no Cepeusp; os colegas da turma de mestrado e os amigos do IME e do NUMEC.

Os meus amigos chilenos (de Arica a Punta Arenas) que conheci em São Paulo, para eles e elas meus respeitos e carinhos.

Meus amigos que ficaram no Chile, de Loncoche e Temuco, e sempre me apoiaram e expressaram seu carinho. ..y ahora cambiemos el mundo, amigo, que tú ya has cambiado el mio...

Agradeço muito especialmente ao meu amigo Roberto e a sua esposa Han, pela ajuda e apoio no meu primeiro ano longe da minha terra, e pelas contribuições neste trabalho. 


\section{Resumo}

Neste trabalho estudamos os type-dependent stochastic spin models propostos por Fernández et al. em [9], os que chamaremos de modelos de spins estocástico dependentes de tipo, e que foram usados para modelar redes de sinalização biológica. A modelagem original descreve a evolução macroscópica de um modelo de spin-flip de tamanho finito com $k$ tipos de spins, possuindo um número arbitrário de estados internos, que interagem através de uma dinâmica estocástica não reversível. No limite termodinânico foi provado que, em um intervalo de tempo finito as trajetórias convergem quase certamente para uma trajetória determinística, dada por uma equação diferencial de primeira ordem. Os comportamentos destes sistemas dinâmicos podem incluir bifurcações, relacionadas às transições de fase do modelo.

O nosso objetivo principal foi de estender os modelos de spins com dinâmica de Glauber utilizados em [9], permitindo trocas múltiplas dos spins. No contexto biológico tentamos incluir situações nas quais moléculas de tipos diferentes trocam simultaneamente os seus estados internos. Utilizando diversas técnicas, como as de grandes desvíos e acoplamento, tem sido possível demonstrar a convergência para o sistema dinâmico associado.

Palavras-chave: Modelo de spins estocástico dependente de tipo, rede de sinalização biológica, dinâmica estocástica não reversível, processo de perfil de densidade, convergência quase certa, sistema dinâmico, campo médio. 


\section{Abstract}

We study type-dependent stochastic spin models proposed by Fernández et al. in [9], which were used to model biological signaling networks. The original modeling setup describes the macroscopic evolution of a finite-size spin-flip model with $k$ types of spins with arbitrary number of internal states interacting through a non-reversible stochastic dynamics. In the thermodynamic limit it was proved that, within arbitrary finite time-intervals, the path converges almost surely to a deterministic trajectory determined by a first-order (non-linear) differential equation. The behavior of the associated dynamical system may include bifurcations, associated to phase transitions in the statistical mechanical setting.

Our aim is to extend the spin model with Glauber dynamics used in [9], to allow multiple spin-flips. In the biological context we included situations in which molecules of different types simultaneously change their internal states. Using several methods, such as large deviations and coupling, we prove the convergence theorem.

Keywords: Type-dependent stochastic spin model, biological signaling network, non-reversible stochastic dynamics, density-profile process, almost sure convergence, dynamical system, mean field. 


\section{Sumário}

$\begin{array}{ll}\text { Lista de Abreviaturas } & \text { ix }\end{array}$

Lista de Símbolos

Lista de Figuras $\quad$ xiii

1 Introdução 1

1.1 Considerações preliminares . . . . . . . . . . . . . . . . . . 1

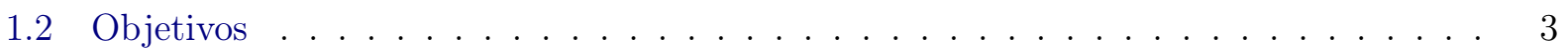

1.3 Contribuições . . . . . . . . . . . . . . . . . . . . 3

1.4 Organização do trabalho . . . . . . . . . . . . . . . . . . . . . 4

2 Uma Classe de Modelos de Spins Estocásticos 5

2.1 Modelos de spins estocástico dependentes de tipo . . . . . . . . . . . . . . . 5

2.2 Processos de perfil de densidade . . . . . . . . . . . . . . . . . 9

2.3 Extensão do modelo de spins estocástico dependente de tipo . . . . . . . . . . . . . 12

2.3.1 Modelo de spins estocástico com trocas múltiplas . . . . . . . . . . . . . . . . 12

2.3.2 Processo de perfil de densidade associado $\left\{w_{t}^{x^{0}, N}\right\}_{t \geq 0} \ldots \ldots \ldots \ldots$

3 Redes de Sinalização Biológica $r$

3.1 Análise multi-nível e exemplos de módulos de interação . . . . . . . . . . . . . . . . 19

3.2 Módulos de interação com trocas múltiplas . . . . . . . . . . . . . . . . . . . . . . 24

4 Principais Resultados $\quad 27$

4.1 Teorema de convergência para $\left(m_{t}^{x^{0}, N}\right)_{N} \ldots \ldots \ldots \ldots \ldots \ldots \ldots \ldots$

4.2 Teorema de convergência para $\left(w_{t}^{x^{0}, N}\right)_{N} \ldots \ldots \ldots \ldots \ldots$

4.3 Análise de bifurcações para o módulo de interação cíclica . . . . . . . . . . . . . . . 29

5 Demonstrações $\quad 35$

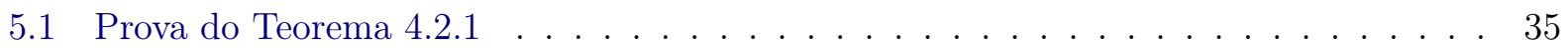

$5.1 .1 \quad$ O processo auxiliar . . . . . . . . . . . . . . . . . . . 35

5.1 .2 Processo de discrepância e acoplamento principal . . . . . . . . . . . . . . 37

5.1 .3 Controle do processo de discrepância . . . . . . . . . . . . . . . . . . . . . 41 
viii SUMÁRIO

5.2 Prova dos resultados das análises de bifurcações . . . . . . . . . . . . . . . . 45

$5.2 .1 \quad$ Prova do Teorema $4.3 .1 \ldots \ldots \ldots \ldots$

5.2 .2 Prova da Proposição $4.3 .2 \ldots \ldots$. . . . . . . . . . . . . . . . 46

Referências Bibliográficas $\quad 49$ 


\title{
Lista de Abreviaturas
}

\author{
Mdm2 Proteína Mdm2 (Murine Double minute 2). \\ NF- $\kappa$ B Fator nuclear kappa B (nuclear factor kappa-light-chain-enhancer of activated $B$ cells). \\ $\mathrm{I} \kappa \mathrm{B} \quad$ Inibidor de $\kappa \mathrm{B}$ (Inhibitor of $\kappa B$ ). \\ IKK Quinase do $\mathrm{I} \kappa \mathrm{B}(I \kappa B$ kinase $)$.
}




\section{Lista de Símbolos}

$\mathbb{R} \quad$ Conjunto dos Números Reais.

$\mathbb{N} \quad$ Conjunto dos Números Naturais.

$\mathcal{P}(A) \quad$ Conjunto das Partes de A.

$\mathbf{1}_{A} \quad$ Função Indicadora do Evento $A$.

$\varlimsup_{N} \quad$ Limite Superior com $N \rightarrow \infty$.

$\underline{\lim }_{N} \quad$ Limite Inferior com $N \rightarrow \infty$.

$\operatorname{Multi}(n, \mathbf{p})$ Distribuição Multinomial de Parâmetros $n$ e $\mathbf{p}, \operatorname{com} \mathbf{p}=\left(p_{1}, \ldots, p_{k}\right)$.

$\operatorname{Bin}(n, p) \quad$ Distribuição Binomial de Parâmetros $n$ e $p$.

i.i.d. Independentes Identicamente Distribuidas. 


\section{Lista de Figuras}

2.1 Exemplo do sistema de spins definido no modelo. Nas horizontais encontramos as posições espaciais e os tipos de spins são representados nas verticais. Neste caso, temos que $|\mathcal{T}|=5$ e $N=6$. O spin aumentado mostra a notação utilizada $\eta(i, n) \in \mathcal{S}_{i}$. . . . . . . . . . . . . . . . . . . . . . . . . . . . . . . 6

2.2 Exemplo da transição associada à trinca $\left(A, \sigma_{A}, \bar{\sigma}_{A}\right), \operatorname{com} A=\{i, j, k\}$ e $\sigma_{A}, \bar{\sigma}_{A} \in \mathcal{S}_{A}$. . . . . . . . . . . 13

3.1 Exemplo da rede de sinalização biológica associada à decisão entre proliferação e apoptose. As setas indicam uma interação de ativação do componente bioquímico no início da seta com o componente na sua ponta; similarmente, setas sem ponta indicam inibição. Imagem obtida de [17]. . . . . . . . . . . . . . . . .

3.2 Módulo do relógio básico baseado em uma sequência de feedback de inibição entre três componentes indicados por $A, B$ e $C$. As setas sem ponta indicam inibição. . . . . . . . . . . . . . . . . . . . . . . . . .

3.3 Possíveis transições correspondentes às interações p53/Mdm2 dadas por T. Zhang et al. [34]; setas sólidas indicam transições. setas tracejadas desde um estado até uma seta sólida indicam que a taxa de transição é regulada pela densidade do estado inicial. . . . . . . . . . . . . . . . . . . . . . . . . . . . .

3.4 Modelo de Ising com trocas múltiplas dos spins, caracterizando a mesma interação da Figura 3.3. Setas duplas identificam transições duplas; a seta dupla com um ponto no início representa o passo de uma molécula de mdm2 do citoplasma para o núcleo, enquanto a seta com um diamante no início representa o trajeto inverso.

$3.5 \mathrm{O}$ módulo de sinalização I $\kappa \mathrm{B}-\mathrm{NF}-\kappa \mathrm{B}$ de A. Hoffmann et al. [12]. NF- $\kappa \mathrm{B}$ é segurado inativo no citoplasma pelos três isomorfos de $\mathrm{I} \kappa \mathrm{B}$. A estimulação celular ativa o complexo IKK, levando à forforilação e degradação das proteínas de $\mathrm{I} \kappa \mathrm{B}$. O NF- $\kappa \mathrm{B}$ liberado é conduzido ao núcleo, ativando genes, incluindo o $\mathrm{I} \kappa \mathrm{B} \alpha$. I $\kappa \mathrm{B} \beta$ e - $\varepsilon$ são sintetizados com taxas constantes, permitindo um complexo controle temporal da ativação de NF- $\kappa \mathrm{B}$, envolvendo um feedback negativo. . . . . . . . . . . . . . . . . . . . . . . . . . . . . . . . . .

4.1 Exemplo de interação assimétrica de quatro componentes. Neste caso, as setas representam uma interação genérica. Porém, conhecendo os valores de $s_{i}$ elas teriam de representar produção ou inibição. . . . . . . .

4.2 Diagrama de bifurcação para o relógio básico assimétrico ferromagnético, com $\delta=0.3$. As linhas sólidas representam pontos estáveis; linhas tracejadas indicam pontos inestáveis. Diagrama obtido com xppaut [7]. .

4.3 Diagrama de bifurcação para o relógio básico assimétrico antiferromagnético, $\operatorname{com} \delta=0.1$. Vemos a bifurcação de tipo Hopf com respeito ao parâmetro $J$, que mede a força da interação. Linhas sólidas representam pontos estáveis; linhas tracejadas indicam pontos inestáveis; pontos pretos indicam valores máximos e mínimos das órbitas estáveis. Diagrama realizado com xppaut [7]. . . . . . . . . . . . . . . . . . . . . . . . . . 


\section{Capítulo 1}

\section{Introdução}

Cada vez é mais claro que a complexidade dos processos biológicos e bioquímicos tornam essencial o trabalho multidisciplinar. Particularmente, o crescente uso da matemática na área da biologia tem sido exposto por varios autores (ver, por exemplo, [1, 2, 30]). Já no ano 1983, Segel editou um livro [25] para apresentar as possíveis utilidades da aplicação de modelos matemáticos na área da biologia celular e molecular. Da mesma forma, Murray [21] expressou que a união entre as duas ciências era inevitável para que a biologia se tornasse mais quantitativa.

No ano 1999, Hartwell et al. [11] convidaram os científicos da área da biologia para uma nova abordagem teórica na área de biologia molecular da célula, dizendo que o melhor teste para o entendimento das células sería fazer predições quantitativas testáveis, sobre o comportamento destas e o seu ambiente. Para Chong e Ray [4], isto põe em evidência que o progresso no entendimento desses processos precisa do desenvolvimento de modelos matemáticos, que ajudem a entender os fenômenos sob consideração. Modelos que também colaboram a quantificar e conceptualizar o processamento de informação e as suas propriedades dinâmicas (Sontag [26]).

Segundo Murray [21] a biologia abre novas e excitantes áreas de estudo para os matemáticos, enquanto para os biólogos, a modelagem matemática oferece outras ferramentas de pesquisa comparáveis com uma poderosa nova técnica de laboratório, mas somente se for usada apropriadamente e compreendendo as suas limitações.

\subsection{Considerações preliminares}

Um problema central na área da biologia é de entender como as células comunicam-se e respondem adequadamente aos sinais do ambiente. Muitos sinais biológicos são recebidos e transmitidos por meio de sequências de reações bioquímicas que serão chamadas redes de sinalização biológica quando o fluxo de informação é o principal interesse. Nestas cadeias a informação extracelular é usualmente transmitida através de receptores da membrana celular ativados por entidades químicas 
conhecidos como ligandos, tais como hormônios, neurotransmissores ou fatores do crescimento. Assim, estes sinais causam complexas cascatas de interações bioquímicas no interior da célula, as quais dependem do tempo e podem conduzir a diferentes respostas, tais como embriogênese, motilidade, diferenciação e apoptose (conhecida como morte celular programada).

Um fato importante de estudar redes de sinalização é que estas podem exibir mecanismos de controle bastante similares aos achados em engenharia de sistemas, os que permitem à celula sobreviver a fortes pressões seletivas para um bom desempenho e, portanto, ser capaz de implementar estratégias eficazes de prevenção de respostas fisiológicas inadequadas. Porém, maus funcionamentos nestes circuitos bioquímicos e os seus mecanismos de controle poderiam levar a condições patológicas, tais como o câncer.

Avanços no entendimento das redes de sinalização e os mecanismos de controle precisam do desenvolvimento de modelos matemáticos que possuam bom equilíbrio entre simplicidade e utilidade. Estes modelos poderiam ajudar a entender o comportamento dinâmico das redes, além de gerar predições experimentalmente verificáveis.

Embora existe um grande número de trabalhos envolvendo modelagem matemática nos processos biológicos de diferente nível (ver, por exemplo, [3, 20, 24]), a maioria deles usa modelos baseados em equações diferenciais. Usualmente para obter o sistema dinâmico descrito por uma certa rede de sinalização é preciso recorrer às ideias de cinética química, tais como a lei de ação de massas descrita por Keener e Sneyd em [13] e equações do tipo Michaelis-Menten, a qual foi desenvolvida originalmente sob condições fortemente simplificadas.

Contudo, nos últimos anos tem sido estudados alguns processos estocásticos que, no limite termodinâmico, comportam-se de forma similar a uma equação diferencial ordinária. Desta maneira é possível fazer predições aproximadas dos comportamentos dos sistemas estocásticos. Uma interessante revisão destes processos pode ser encontrada no artigo de Durrett [6].

Desta forma, pensando em explicar os comportamentos de algumas redes de sinalização biológica, Fernández et al. [9] propõem um enfoque alternativo baseado nas ideias dos sistemas de partículas interagentes para derivar o sistema dinâmico associado, esta modelagem tenta incorporar informação qualitativa essencial sobre as interações bioquímicas. Assim, definindo os chamados modelos de spins estocásticos dependentes de tipo, para os projetar em um processo de saltos chamado de perfil de densidade; prova-se no limite termodinâmico, que em um intervalo de tempo finito as trajetórias convergem quase certamente para uma trajetória determinística dada por uma equação diferencial de primeira ordem. O comportamento destes sistemas dinâmicos podem incluir bifurcações, relacionadas às transições de fase do modelo.

Segundo os autores, tal alternativa torna-se importante dado que um problema associado ao 
enfoque usual é a dificuldade de estender as conclusões das análises devido a que elas dependem de uma escolha, um tanto arbitrária das equações. Por outro lado, esta nova forma de modelar redes de sinalização biológica tem obtido bons resultados, apresentados através da análise de bifurcações dos sistemas dinâmicos associados. No caso particular da interação das moléculas p53 e mdm2, o sistema dinâmico tem comportamentos similares aos expostos por outros pesquisadores, entre eles Zhang et al. [34].

\subsection{Objetivos}

O objetivo principal é estender os modelos de spins estocásticos dependentes de tipo com dinâmica de Glauber definidos em [9], permitindo agora trocas múltiplas dos spins. No contexto biológico tentamos incluir situações nas quais moléculas de tipos diferentes trocam simultaneamente os seus estados internos. Desta forma, propomos uma maneira de descrever a evolução do modelo para obter o drift associado que permita esclarecer a convergência para o sistema dinâmico referente.

Fazemos notar que a prova da convergência apresentada pelos autores utilizou técnicas como as de acoplamento e grandes desvíos. Embora uma alternativa a isto é encontrada no livro de S. Ethier e T. Kurtz [8], que estudam uma família de processos markovianos de saltos dependentes de um parâmetro. No caso, propõem uma forma de provar a convergência dos processos populacionais dependentes da densidade, para um sistema dinâmico associado. Tais noções são baseadas no problema do martingale desenvolvido originalmente por D. Stroock e S.R.S. Varadhan em [28] para construir e estudar processos de difusão com coeficientes contínuos.

Contudo, a nossa demonstração é absolutamente baseada nas ferramentas utilizadas por Fernández et al. [9]. Assim, utilizando técnicas similares às por eles empregadas, procura-se demonstrar a convergência entre o processo estocástico e o sistema dinâmico associado.

\subsection{Contribuições}

As principais contribuições deste trabalho são as seguintes:

- Estender os modelos propostos por Fernández et al. [9] para serem aplicados a outros módulos de sinalização biológica, particularmente aquelas em que diferentes tipos de moléculas mudam simultaneamente os seus estados internos, demonstrando a convergência quase certa das trajetórias estocásticas para uma trajetória determinística dada por um sistema dinâmico associado.

- Obter novos resultados na análise de bifurcações apresentada por Fernández et al. [9], estudando o comportamento do que chamamos de relógio básico assimétrico. 


\subsection{Organização do trabalho}

No Capítulo 2, apresentamos a formulação matemática e as propriedades dos modelos de spins estocásticos propostos em [9]. Além disso, incluímos nossa extensão de tais modelos e definimos os processos de perfil de densidade associados. O Capítulo 3 define as propriedades das redes de sinalização, e mostra alguns exemplos dos chamados módulos de interação, para ilustrar as motivações e aplicações dos mencionados modelos. No Capítulo 4 expomos os principais resultados associados à modelagem das redes de sinalização; enunciando os teoremas de convergência para os modelos de spins estocásticos originais e os referidos à nossa extensão, além de uma análise de bifurcações com um interessante resultado. O Capítulo 5 exibe as demonstrações dos resultados enunciados no capítulo anterior. 


\section{Capítulo 2}

\section{Uma Classe de Modelos de Spins Estocásticos}

Neste capítulo, apresentamos o enfoque proposto por R. Fernández et al. [9], para modelar redes de sinalização biológica. Este é baseado nas ideias dos sistemas de partículas interagentes, expostas por T. Liggett em [16], e será descrito como um sistema de spin-flip com $k$ tipos de spins, possuindo um número arbitrário de estados internos, os quais interagem através de uma dinâmica de Glauber estocástica não reversível. Assim, as densidades discretizadas dos diferentes tipos de spins para cada um dos seus estados internos (componentes bioquímicos nas redes de sinalização) serão representadas por um processo de saltos em $\mathbb{R}^{\mathcal{E}}$ ( $\mathcal{E}$ a ser definido) chamado processo de perfil de densidade.

Dado que existem outro tipo de redes de sinalização mais complexas, como definidas na Seção 3.2. Damos passo à nossa extensão do modelo de spins, a qual será definida na Seção 2.3 .

\subsection{Modelos de spins estocástico dependentes de tipo}

Será definida uma família de modelos de spin-flip estocásticos que estendem a definição usual dada por T. Liggett [16], permitindo uma dependência assimétrica das taxas com respeito à função de energia, o Hamiltoniano. Esta família será chamada de modelos estocásticos dependentes de tipo, os quais possuem uma importância matemática própria.

Considere $\mathcal{T}$ uma família finita de tipos de spins (elementos, componentes, moléculas), com cada $i \in \mathcal{T}$ possuindo espaço de estados $\mathcal{S}_{i}=\left\{a_{1}, \ldots, a_{s_{i}}\right\}$ e, seja também $\Lambda=\{1, \ldots, N\}$, um conjunto finito de posições espaciais. Chamamos de sítios ao par composto por um tipo e uma posição espacial, isto é, o sistema de spins possui espaço de sítios $V=\mathcal{T} \times \Lambda$ e portanto espaço de configurações $\Sigma=\Pi_{i \in \mathcal{T}} \mathcal{S}_{i}^{\Lambda}$. Assim, para uma configuração $\eta \in \Sigma$, o valor de um spin no sítio $(i, n)$-quer dizer, de um spin de tipo $i$ na posição $n$ - é denotado $\eta(i, n)$. (Ver Figura 2.1).

A dinâmica estocástica é dada em tempo contínuo e as mudanças dos spins somente acontecem 


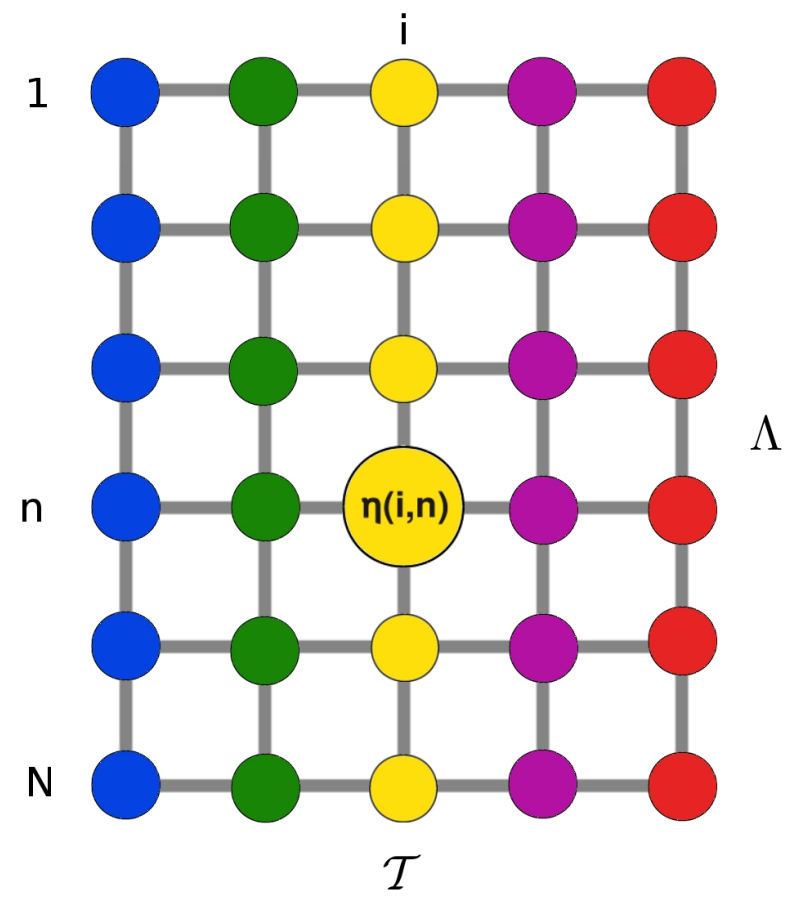

Figura 2.1: Exemplo do sistema de spins definido no modelo. Nas horizontais encontramos as posições espaciais e os tipos de spins são representados nas verticais. Neste caso, temos que $|\mathcal{T}|=5$ e $N=6$. O spin aumentado mostra a notação utilizada $\eta(i, n) \in \mathcal{S}_{i}$.

em um sítio por vez. Em outras palavras, unicamente são permitidas transições individuais do estado interno de algum sítio, isto é, o tipo de interação refere-se à dinâmica de Glauber.

As taxas de transição são definidas em termos do Hamiltoniano, $H: \Sigma \rightarrow \mathbb{R}$, chamado também função de energia do sistema de spins. Denotando,

$$
\mathcal{E}=\left\{\underline{i}=(i, a): i \in \mathcal{T}, a \in \mathcal{S}_{i}\right\} .
$$

O Hamiltoniano é expressado em função de um grupo de matrizes de interação $\mathbb{I}_{n, l}: \mathcal{E} \times \mathcal{E} \rightarrow \mathbb{R}$, sendo uma para cada par de posições espacias $n, l \in \Lambda$. Esta quantidade $\mathbb{I}_{n, l}[(i, a) ;(j, b)]$ indica o tamanho da influência que o spin no sítio $(i, n) \in V$ no estado interno $a \in \mathcal{S}_{i}$ tem sobre o spin no sítio $(j, l) \in V$ que está no estado interno $b \in \mathcal{S}_{j}$. Dada a aplicação biológica do modelo, estas matrizes não são consideradas simétricas. Como veremos na Seção 3.1, em uma certa rede de sinalização poderiamos ter uma molécula de tipo $A$ que ajuda na produção de uma outra molécula de tipo $B$, mas a influência inversa não é encontrada.

Desta maneira, a função de energia é definida por,

$$
H(\eta)=\sum_{(i, n) \in V} H_{(i, n)}(\eta)
$$


com

$$
H_{(i, n)}(\eta)=-\sum_{(j, l) \in V} \mathbb{I}_{l, n}[(j, \eta(j, l)) ;(i, \eta(i, n))]
$$

Observamos que $H_{(i, n)}(\eta)$ descreve a influência coletiva da configuração $\eta$ sobre o spin em $(i, n)$ o qual encontra-se no estado interno $\eta(i, n)$.

O Hamiltoniano (2.2) generaliza as interações de tipo Potts usuais em mecânica estatística (ver [33]). Este fato pode ser comprovado de duas maneiras: primeiro, os parâmetros de acoplamento $\left\{\mathbb{I}_{n, l}\right\}_{n, l \in \Lambda}$ dependem dos estados internos dos spins, e segundo e mais importante, as interações não são assumidas como sendo simétricas. Porém, o modelo é restrito a assumir que ditas interações assimétricas somente estão associadas aos tipos, e não às posições espaciais, isto é

$$
\mathbb{I}_{n, l}[(i, a) ;(j, b)]=\mathbb{I}_{l, n}[(i, a) ;(j, b)],
$$

para $n, l \in \Lambda, i, j \in \mathcal{T}, a \in \mathcal{S}_{i}$ e $b \in \mathcal{S}_{j}$.

Antes de definir outras propriedades a serem cumpridas pelas taxas de transição do processo, estabelecemos algumas notações. Dada uma configuração $\eta \in \Sigma$, um sítio $(i, n)$ e um estado $a \in \mathcal{S}_{i}$ denotamos $\eta_{(i, n)}^{a}$ a configuração com

$$
\left[\eta_{(i, n)}^{a}\right](j, l)=\left\{\begin{aligned}
a & \text { se }(j, l)=(i, n) \\
\eta(j, l) & \text { caso contrário. }
\end{aligned}\right.
$$

Além disso, definimos $\Delta_{(i, n)}^{a \rightarrow b}(\eta)$ o custo de energia da transição $\eta_{(i, n)}^{a}$ para $\eta_{(i, n)}^{b}$. Dada por

$$
\Delta_{(i, n)}^{a \rightarrow b}(\eta)=H\left(\eta_{(i, n)}^{b}\right)-H\left(\eta_{(i, n)}^{a}\right) .
$$

Por causa da assimetría das interações podemos decompor $\Delta_{(i, n)}^{a \rightarrow b}(\eta)$ da seguinte maneira

$$
\Delta_{(i, n)}^{a \rightarrow b}(\eta)=\Delta[\text { [sobre] }]_{(i, n)}^{a \rightarrow b}(\eta)-\Delta\left[\begin{array}{c}
\text { para } \\
\text { outros }
\end{array}\right]_{(i, n)}^{a \rightarrow b}(\eta)
$$

Onde o termo

$$
\Delta\left[\begin{array}{c}
\text { sobre } \\
\text { ele }
\end{array}\right] \underset{(i, n)}{a \rightarrow b}(\eta)=\sum_{(j, l) \in V}\left(\mathbb{I}_{l, n}[(j, \eta(j, l)) ;(i, b)]-\mathbb{I}_{l, n}[(j, \eta(j, l)) ;(i, a)]\right),
$$

indica a mudança na influência da configuração $\eta$ sobre o sítio $(i, n)$ quando o estado interno troca de $a$ para $b$, e o termo,

$$
\Delta[\underset{\text { outros }}{\text { para }}]_{(i, n)}^{a \rightarrow b}(\eta)=\sum_{(j, l) \in V}\left(\mathbb{I}_{l, n}[(i, b) ;(j, \eta(j, l))]-\mathbb{I}_{l, n}[(i, a) ;(j, \eta(j, l))]\right)
$$


reflete a troca na influência que o sítio $(i, n)$ tem sobre todos os outros sítios quando o seu estado interno muda de $a$ para $b$.

Indicamos que no trabalho de R. Fernández et al. [9] foi adotada uma prescrição de tipo banho térmico (heat-bath) para a dinâmica do modelo: isto é, cada taxa de transição somente depende da variação da energia trazida sobre o sítio; o resto da configuração atua como um reservatório térmico (heat reservoir) que mantém-se imperturbado. Desta maneira, a taxa $c_{(i, n)}^{a \rightarrow b}(\eta)$ da transição $\eta_{(i, n)}^{a}$

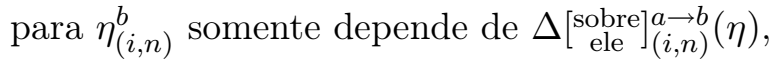

$$
c_{(i, n)}^{a \rightarrow b}(\eta)=\Phi\left(\Delta\left[\begin{array}{c}
\text { sobre } \\
\text { ele }
\end{array}\right] \underset{(i, n)}{a \rightarrow b}(\eta)\right),
$$

em que $\Phi$ é uma função positiva e não crescente que satisfaz a condição

$$
\Phi(E) e^{E}=\Phi(-E) e^{-E}
$$

Quanto às escolhas desta função, a mais natural é das taxas heat-bath

$$
\Phi(E)=e^{-E},
$$

ou a forma de Metropolis

$$
\Phi(E)=e^{-2[E]_{+}},
$$

em que $[x]_{+}=\max \{0, x\}$ é a parte positiva de $x \in \mathbb{R}$.

Sob estas condições, a seguir formaliza-se a definição do modelo dependente de tipo.

\section{Definição 1.}

i) Uma interação dependente de tipo é definida pela prescrição contida em (2.2), (2.3) e (2.4).

ii) Um modelo de spins estocástico dependente de tipo é o processo a tempo continuo definido por um sistema de spins com uma interação dependente de tipo e uma dinâmica com taxas (2.10).

Usualmente nos modelos de spins estocásticos as taxas de transição dependem da variação total da energia associada à transição, isto é

$$
c_{(i, n)}^{a \rightarrow b}(\eta)=\Phi\left(\Delta_{(i, n)}^{a \rightarrow b}(\eta)\right)
$$


Deste modo, o custo total da energia também inclui a variação da energia levada para os outros sítios pela transição em $(i, n)$. Se as matrizes $\mathbb{I}_{n, l}$ são simétricas, $\Delta_{(i, n)}^{a \rightarrow b}(\eta)=2 \Delta$ [sobre ele $_{(i, n)}^{a \rightarrow b}(\eta)$. Isto define os chamados modelos de spins estocásticos em [16], os quais são reversíveis sob a medida de Gibbs

$$
\mu(\eta)=\frac{e^{-H(\eta)}}{\sum_{\xi \in \Sigma} e^{-H(\xi)}}
$$

Destacamos que com taxas dadas por (2.14) a ideia de simetría ou assimetría do acoplamento não tem importancia e o processo é sempre reversível com respeito à medida de Gibbs (2.15). Mas, com as taxas propostas em (2.10), o processo com interação dependente de tipo com acoplamento assimétrico não é mais reversível para a medida de Gibbs. Porém, esta dinâmica é a única que conduz às equações de Kolmogorov (que serão apresentadas em (5.3)), e portanto ao sistema dinâmico em (2.28).

A falta de reversibilidade pode levar às dinâmicas frustradas como veremos na Seção 4.3, sob o modelo de campo médio. Este tipo de modelos chamados de campo médio, são usados pela motivação biológica do trabalho e serão definidos da seguinte maneira.

Definição 2. Um modelo de spins estocástico dependente de tipo é campo médio se os parâmetros do Hamiltoniano em (2.3) são da forma

$$
\mathbb{I}_{n, l}[(i, a) ;(j, b)]=\frac{\alpha_{(i, a),(j, b)}}{|\Lambda|},
$$

em que $\left\{\alpha_{\underline{i}, \underline{j}}\right\}_{\underline{i}, \underline{j} \in \mathcal{E}}$, é uma matriz real.

Assim, baseado na versão de campo médio dos modelos de spins estocásticos dependentes de tipo, a seguir apresentamos a forma de representar as densidades discretizadas dos diferentes tipos de spins. Isto, como veremos mais adiante, com a finalidade de identificar as concentrações dos componentes bioquímicos para uma rede de sinalização biológica.

\subsection{Processos de perfil de densidade $\left\{m_{t}^{x^{0}, N}\right\}_{t \geq 0}$}

O sistema de spins estocástico acima definido será projetado em um processo de saltos em $\mathbb{R}^{\mathcal{E}}$, chamado processo de perfil de densidade, que representará as densidades dos componentes bioquímicos na rede de sinalização biológica, as quais são a principal motivação do trabalho.

Definição 3. Seja $\mathcal{T}$ uma família de tipos com $|\mathcal{T}|=k$. Seja também $\mathcal{S}_{i}=\left\{a_{1}, \ldots, a_{s_{i}}\right\}$ o espaço de estados associado a cada tipo $i \in \mathcal{T}$. Um processo de perfil de densidade em $\mathcal{E}$ será definido 
como um processo de saltos no hipercubo $\mathcal{D}_{N}=\left(-\frac{1}{N}, 1+\frac{1}{N}\right)^{\mathcal{E}}$, para $N \geq 1$, com evolução em tempo continuo. A cada salto, um ponto $x \in \mathcal{D}_{N}$ troca simultaneamente duas coordenadas: uma aumenta em $1 / N$ e outra diminui na mesma quantidade, ambas correspondentes ao mesmo tipo.

As taxas de transição deste processo dependem suavemente da posição $x$. Para defini-las denotamos uma família de matrizes de funções de Lipschitz limitadas $\left(\lambda_{i}^{a \rightarrow b}\right)_{a, b \in \mathcal{S}_{i}}$, uma para cada tipo $i \in \mathcal{T}$, com cada $\lambda_{i}^{a \rightarrow b}: \mathbb{R}^{\mathcal{E}} \rightarrow \mathbb{R}_{+}$e $\lambda_{i}^{a \rightarrow a}=0$. Assim, estas definem as funções $f_{i}^{a \rightarrow b}: \mathbb{R}^{\mathcal{E}} \rightarrow \mathbb{R}_{+}$ através da relação

$$
f_{i}^{a \rightarrow b}(x)=x_{(i, a)}^{\bullet} \lambda_{i}^{a \rightarrow b}\left(x^{\bullet}\right)
$$

para $i \in \mathcal{T}, a, b \in \mathcal{S}_{i}$, em que

$$
x_{\underline{i}}^{\bullet}=\left\{\begin{aligned}
x_{\underline{i}} & \text { se } 0 \leq x_{\underline{i}} \leq 1 \\
0 & \text { se } x_{\underline{i}}<0 \\
1 & \text { se } x_{\underline{i}}>1
\end{aligned}\right.
$$

isto permite assegurar que tais funções serão restritas às trajetórias no hipercubo, ou de outro modo, forçarão às trajetórias a manter-se em $\mathcal{D}_{N}$. Este fato será esclarecido mais adiante em concordância à conexão com os sistemas microscópicos e, à aplicação a ser considerada.

Um processo de perfil de densidade denotado por $\left\{m_{t}^{x^{0}, N}\right\}_{t \geq 0}$, é um passeio aleatório em $\mathcal{D}_{N}$ que começa no ponto $x^{0}$ e evolui em tempo contínuo através de saltos da forma

$$
x \rightarrow x-\frac{e_{(i, a)}}{N}+\frac{e_{(i, b)}}{N},
$$

em que $e_{\underline{i}}$ é o vetor unitário na direção de $\underline{i}$. Para cada posição $x \in \mathcal{D}_{N}$ tal transição ocorre com taxa $N f_{i}^{a \rightarrow b}(x)$, isto é,

$$
N f_{i}^{a \rightarrow b}(x)=\left.\frac{d}{d t} P\left(m_{t}^{x, N}=x-\frac{e_{(i, a)}}{N}+\frac{e_{(i, b)}}{N}\right)\right|_{t=0}
$$

Cada variável $x_{(i, a)}$ representa a densidade dos elementos de tipo $i$ que estão no estado interno $a \in \mathcal{S}_{i}$, e a função $\lambda_{i}^{a \rightarrow b}$ é a taxa com que um elemento do tipo $i$ troca o seu estado de $a \in \mathcal{S}_{i}$ para $b \in \mathcal{S}_{i}$ (no sistema microscópico).

Para explicitar a conexão entre os modelos de spins estocásticos dependentes de tipo e os processos de perfil de densidade aqui definidos, diremos que para cada modelo de spins, uma configuração $\eta \in \Sigma$ terá como perfil de densidade empírico $m(\eta)=\left(m_{\underline{i}}(\eta)\right)_{\underline{i} \in \mathcal{E}} \in \mathbb{R}_{+}^{\mathcal{E}}$, com

$$
m_{(i, a)}(\eta)=\frac{|\{n \in \Lambda: \eta(i, n)=a\}|}{|\Lambda|}
$$

para $i \in \mathcal{T}$ e cada $a \in \mathcal{S}_{i}$. Logo, quando nos referimos a um salto do tipo (2.19), para um dado processo de perfil de densidade, este estará associado à transição da configuração $\eta_{(i, n)}^{a}$ para $\eta_{(i, n)}^{b}$ 
em um sistema de spins com $m(\eta)=x$. Em razão disso, na equação (2.20) o termo $N f_{i}^{a \rightarrow b}$ é a taxa total de transição $a \rightarrow b$ para todos os $N x_{(i, a)}$ elementos do tipo $i$ no estado $a \in \mathcal{S}_{i}$ presentes nos diferentes sítios.

Fixando o valor de $N$, que representa o número total de partículas de cada tipo, definimos o conjunto de estados iniciais que satisfazem a seguinte condição,

$$
\mathcal{H}_{\mathcal{E}}=\left\{x \in[0,1]^{\mathcal{E}}: \sum_{a \in S_{i}} x_{(i, a)}=1, i \in \mathcal{T}\right\}
$$

Desde agora, dada a aplicação do modelo, supomos que as trajetórias dos processos de perfil de densidade $\left\{m_{t}^{x^{0}, N}\right\}_{t \geq 0} \in \mathcal{D}_{N}$ também pertencem a $\mathcal{H}_{\mathcal{E}}$. Consequentemente, podemos nos desfazer da notação de (2.18).

Seja $\left\{m_{t}^{x^{0}, N}\right\}_{t \geq 0}$ o processo de perfil de densidade em $\mathcal{D}_{N}$, definido para apropriadas funções $\lambda_{i}^{a \rightarrow b}$. O drift associado, dado por uma função $V: \mathbb{R}^{\mathcal{E}} \rightarrow \mathbb{R}_{+}^{\mathcal{E}}$, será expressado como:

$$
V(x)=\lim _{t \rightarrow 0} \frac{\mathbf{E}\left(m_{t}^{x, N}-x\right)}{t} .
$$

Denotamos $\left(m_{t}^{x, N}\right)_{(i, b)}$ o processo de perfil de densidade na direção coordenada $(i, b)$ no instante $t \geq 0$. Logo, usamos as seguintes propriedades dos processos de Poisson

$$
P\left(\left(m_{t}^{x, N}\right)_{(i, b)}=y\right)=\left\{\begin{aligned}
N \cdot\left(\sum_{a \in \mathcal{S}_{i}} f_{i}^{a \rightarrow b}\right) t+o(t) & \text { se } y-x=\frac{1}{N} \\
N \cdot\left(\sum_{a \in \mathcal{S}_{i}} f_{i}^{b \rightarrow a}\right) t+o(t) & \text { se } x-y=\frac{1}{N} \\
o(t) & \text { se }|y-x| \geq \frac{2}{N}
\end{aligned}\right.
$$

com $o(t)$ referente a uma função definida por:

$$
f(t)=o(t) \Longleftrightarrow \lim _{t \rightarrow 0} \frac{f(t)}{t}=0
$$

Então obtemos,

$\mathbf{E}\left(\left(m_{t}^{x, N}\right)_{(i, b)}-x_{(i, b)}\right)=\frac{1}{N}\left[N \cdot\left(\sum_{a \in \mathcal{S}_{i}} f_{i}^{a \rightarrow b}\right) t+o(t)\right]-\frac{1}{N}\left[N \cdot\left(\sum_{a \in \mathcal{S}_{i}} f_{i}^{b \rightarrow a}\right) t+o(t)\right]+o(t)$.

Dividindo em $t$ e aplicando limite:

$$
\lim _{t \rightarrow 0} \frac{\mathbf{E}\left(\left(m_{t}^{x, N}\right)_{(i, b)}-x_{(i, b)}\right)}{t}=\sum_{a \in \mathcal{S}_{i}} f_{i}^{a \rightarrow b}-\sum_{a \in \mathcal{S}_{i}} f_{i}^{b \rightarrow a} .
$$


Considerando (2.17), segue então o valor do drift associado à coordenada $(i, b)$

$$
V_{(i, b)}(x)=\sum_{a \in S_{i}} x_{(i, a)} \lambda_{i}^{a \rightarrow b}(x)-x_{(i, b)} \sum_{a \in S_{i}} \lambda_{i}^{b \rightarrow a}(x)
$$

Neste momento introduzimos o processo determinístico para o qual provaremos a convergência do nosso modelo aleatório. Portanto, definimos $\left\{x_{t}^{x^{0}}\right\}_{t \geq 0}$ como solução do sistema dinâmico

$$
\dot{x}_{t}=V\left(x_{t}\right),
$$

começando em $x^{0} \in \mathcal{H}_{\mathcal{E}}$. A trajetória global existe pela suavidade do campo $V$. Além disso, o fluxo jamais abandona $[0,1]^{\mathcal{E}}$ se a condição inicial pertence a $\mathcal{H}_{\mathcal{E}}$. De fato, neste caso, cada $V_{\underline{i}}$ fica estritamente positivo se $x_{\underline{i}}$ atinge 0 e é estritamente negativo se $x_{\underline{i}}$ atinge 1 .

\subsection{Extensão do modelo de spins estocástico dependente de tipo}

Considerando uma interação de moléculas com condições como as que serão descritas na Seção 3.2, propomos uma extensão do modelo acima definido. Isto é, no modelo microscópico são permitidas transições simultâneas dos estados internos de diferentes tipos de spins. Neste sentido, os tipos de spins que em um determinado instante trocam os seus estados internos, serão denotados pelo subconjunto $A \in \mathcal{P}(\mathcal{T})$. Assim, o novo modelo incluirá taxas de transição múltipla que generalizam os processos definidos por R. Fernández et al. [9]. De fato, quando $A=\{i\}$, obtemos como caso particular o modelo por eles proposto.

Neste caso o novo modelo global não apresenta uma evolução de tipo Glauber. Porém, como veremos mais adiante para cada tipo $i \in \mathcal{T}$ mantém-se uma dinâmica com essas características.

\subsubsection{Modelo de spins estocástico com trocas múltiplas}

O novo sistema microscópico de spins será denotado como um processo $\left\{\eta_{t}\right\}_{t \geq 0} \in \Sigma=\prod_{i \in \mathcal{T}} \mathcal{S}_{i}^{\Lambda}$. A sua evolução ficará definida da seguinte maneira: dada uma configuração $\eta \in \Sigma$, associamos um processo de Poisson a cada trinca composta por um conjunto de tipos de spins $A \in \mathcal{P}^{*}(\mathcal{T})=\mathcal{P}(\mathcal{T}) \backslash$ $\{\emptyset\}$, e dois vetores de estados internos referentes aos tipos $i \in A$, denotados $\sigma_{A}, \bar{\sigma}_{A} \in \mathcal{S}_{A}=\prod_{i \in A} \mathcal{S}_{i}$, $\operatorname{com} \bar{\sigma}_{A}(i) \neq \sigma_{A}(i), \forall i \in A$. A taxa destes processos será

$$
\frac{\Theta_{A}^{\sigma_{A} \rightarrow \bar{\sigma}_{A}}(m(\eta))}{G_{A}(N)},
$$


com $m(\eta)=\left(m_{\underline{i}}(\eta)\right)_{\underline{i} \in \mathcal{E}} \in \mathbb{R}_{+}^{\mathcal{E}}$ como definido em $(2.21)$, e $G_{A}(N)$ uma função polinomial que reescala as taxas para os diferentes subconjuntos $A \in \mathcal{P}^{*}(\mathcal{T})$. O papel desta função no controle do comportamento do processo e as características das funções $\Theta_{A}^{\sigma_{A} \rightarrow \bar{\sigma}_{A}}$ serão expressas na subseção seguinte.

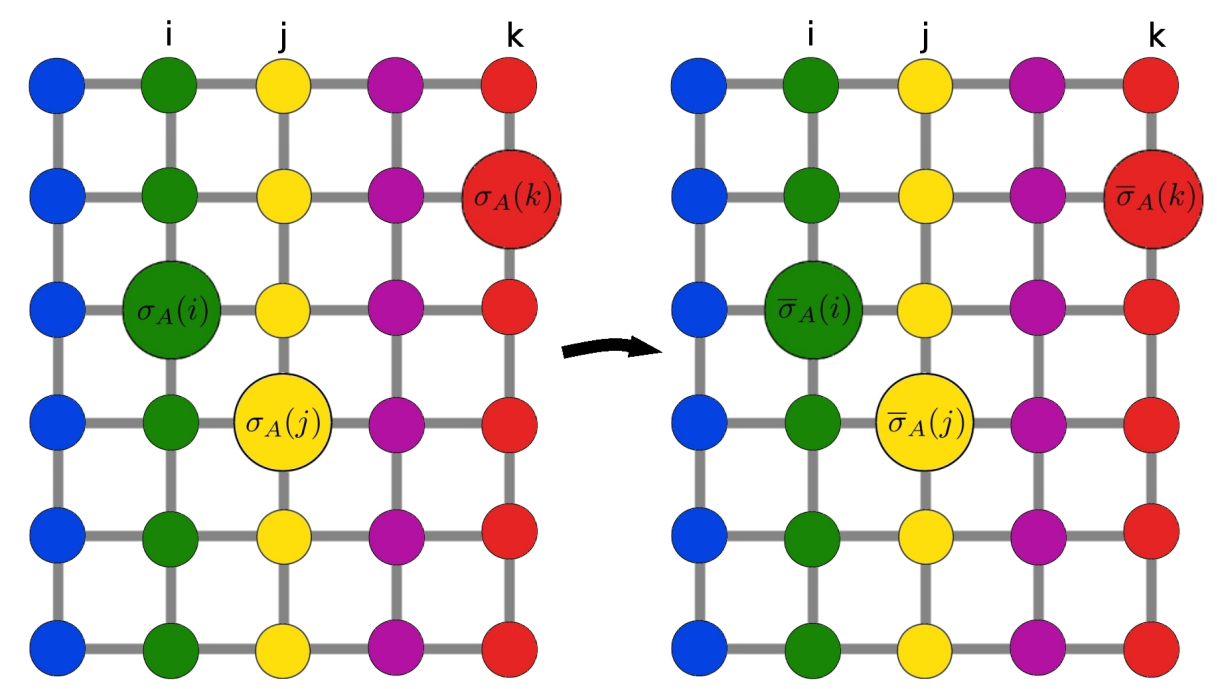

Figura 2.2: Exemplo da transição associada à trinca $\left(A, \sigma_{A}, \bar{\sigma}_{A}\right)$, com $A=\{i, j, k\}$ e $\sigma_{A}, \bar{\sigma}_{A} \in \mathcal{S}_{A}$.

De outra forma, para cada $\eta \in \Sigma$ indicamos $K$ processos de Poisson independentes, com

$$
K=\sum_{A \in \mathcal{P}^{*}(\mathcal{T})} \prod_{i \in A}\left|\mathcal{S}_{i}\right|\left(\left|\mathcal{S}_{i}\right|-1\right)
$$

Cada um destes processos trazem a indicação de trocar um único spin para cada tipo $i \in A$, o qual encontra-se no estado interno $\sigma_{A}(i)$ e mudará para o estado $\bar{\sigma}_{A}(i)$ (Ver Figura 2.2). Logo, notamos que esta indicação será obedecida dependendo do número de sítios candidatos para cada $i \in A$, quer dizer, o número de spins no estado interno $\sigma_{A}(i)$ para cada tipo. Desta forma, o processo de Poisson associado à trinca $\left(A, \sigma_{A}, \bar{\sigma}_{A}\right)$, será aceito por cada tipo $i \in A$ de forma independente e com uma probabilidade $p_{i, \sigma_{A}(i)}(m(\eta))$, dada por

$$
p_{i, \sigma_{A}(i)}(m(\eta))=m_{\left(i, \sigma_{A}(i)\right)}(\eta) .
$$

Portanto, com probabilidade $p_{A, \sigma_{A}}(m(\eta))=\prod_{i \in A} p_{i, \sigma_{A}(i)}(m(\eta))$ aprovamos a troca proposta; caso contrário, esta é desprezada. Uma vez aceita uma transição associada a $\left(A, \sigma_{A}, \bar{\sigma}_{A}\right)$, escolhemos os sítios específicos a serem trocados. Obviamente, precisamos indicar um vetor de posições espacias $n_{A} \in \Lambda^{|A|}$ (com coordenadas denotadas por $n_{A}(i) \in \Lambda$, para cada $i \in A$ ) satisfazendo $\eta_{\left(A, n_{A}\right)}=\sigma_{A}$, 
o que equivale a dizer $\eta=\eta_{\left(A, n_{A}\right)}^{\sigma_{A}}$, com

$$
\left[\eta_{\left(A, n_{A}\right)}^{\sigma_{A}}\right](i, n)=\left\{\begin{aligned}
\sigma_{A}(i) & \text { se } i \in A \text { e } n=n_{A}(i), \\
\eta(i, n) & \text { caso contrário. }
\end{aligned}\right.
$$

Assim, para cada tipo $i \in A$ escolhemos de maneira uniforme, e independente dos outros tipos, qual o sítio a ser trocado. Isto acontece com probabilidade

$$
p_{i, n_{A}(i)}(m(\eta))=\frac{1}{N \cdot m_{\left(i, \sigma_{A}(i)\right)}(\eta)}
$$

Finalmente, dizemos que uma transição da configuração $\eta$ para $\eta_{\left(A, n_{A}\right)}^{\sigma_{A}}$, acontecerá com a seguinte taxa

$$
\begin{aligned}
c\left(\eta, \eta_{\left(A, n_{A}\right)}^{\bar{\sigma}_{A}}\right) & \left.=\sum_{\sigma_{A}} \frac{\Theta_{A}^{\sigma_{A} \rightarrow \bar{\sigma}_{A}}(m(\eta))}{G_{A}(N)} \cdot p_{A, \sigma_{A}}(m(\eta)) \cdot \prod_{i \in A} p_{i, n_{A}(i)}(m(\eta)) \mathbf{1}_{\left\{\eta=\eta_{\left(A, n_{A}\right)}^{\bar{\sigma}_{A}}\right.}\right\} \\
& =\sum_{\sigma_{A}} \frac{\Theta_{A}^{\sigma_{A} \rightarrow \bar{\sigma}_{A}}(m(\eta))}{G_{A}(N) \cdot N^{|A|}} \mathbf{1}_{\left\{\eta=\eta_{\left(A, n_{A}\right)}^{\sigma_{A}}\right\}}
\end{aligned}
$$

Destaca-se que por causa da aplicação biológica assumimos que estas taxas somente dependem da configuração fora dos tipos em $A$. Também observamos que para algum $\eta=\eta_{\left(A, n_{A}\right)}^{\sigma_{A}}=\eta_{\left(A, \bar{n}_{A}\right)}^{\sigma_{A}}$, então $c\left(\eta, \eta_{\left(A, n_{A}\right)}^{\bar{\sigma}_{A}}\right)=c\left(\eta, \eta_{\left(A, \bar{n}_{A}\right)}^{\bar{\sigma}_{A}}\right)$.

É claro, dependendo do processo a ser modelado, as taxas em (2.29) poderão assumir valores nulos para algumas das trincas acima definidas. Além disso, desta construção vemos que no sistema global são permitidas trocas múltiplas dos spins, mas para cada tipo $i \in \mathcal{T}$ unicamente acontecem trocas individuais.

Lembramos que este modelo de spin estocástico é projetado em um processo de saltos, chamado perfil de densidade. A seguir, definimos e analizamos tal processo.

\subsubsection{Processo de perfil de densidade associado $\left\{w_{t}^{x^{0}, N}\right\}_{t \geq 0}$}

O novo processo de perfil de densidade será denotado por $\left\{w_{t}^{x^{0}, N}\right\}_{t \geq 0}$. Incluíndo agora as taxas das novas transições permitidas, é claro que o seu comportamento é mais geral do $\left\{m_{t}^{x^{0}, N}\right\}_{t \geq 0}$ definido anteriormente. Abaixo, estabelecemos algumas notações e principais propriedades do modelo.

Este processo de perfil de densidade em $\mathcal{E}$, continua sendo um processo de saltos no hipercubo $\mathcal{D}_{N}=\left(-\frac{1}{N}, 1+\frac{1}{N}\right)^{\mathcal{E}}$, para $N \geq 1$, que evolui a tempo contínuo. Porém, com saltos que dependem do tamanho do conjunto $A \in \mathcal{P}^{*}(\mathcal{T})$. Isto é, a cada salto associado a $A$, um ponto $x \in \mathcal{D}_{N}$ troca 
simultaneamente $2 \cdot|A|$ coordenadas: um número $|A|$ delas aumenta em $1 / N$ e outras $|A|$ diminuem na mesma quantidade, todas elas correspondentes a $|A|$ pares de diferentes tipos.

As suas taxas de transição são também definidas através de uma família de matrizes de funções de Lipschitz limitadas $\left(\lambda_{A}^{\sigma_{A} \rightarrow \bar{\sigma}_{A}}\right)_{\sigma_{A}, \bar{\sigma}_{A} \in \mathcal{S}_{A}}$, uma para cada $A \in \mathcal{P}^{*}(\mathcal{T})$, com cada $\lambda_{A}^{\sigma_{A} \rightarrow \bar{\sigma}_{A}}: \mathbb{R}^{\mathcal{E}} \rightarrow \mathbb{R}_{+}$, e $\lambda_{A}^{\sigma_{A} \rightarrow \sigma_{A}}=0$. Equivalente a $(2.17)$, definimos as funções $f_{A}^{\sigma_{A} \rightarrow \bar{\sigma}_{A}}: \mathbb{R}^{\mathcal{E}} \rightarrow \mathbb{R}_{+}$como

$$
f_{A}^{\sigma_{A} \rightarrow \bar{\sigma}_{A}}(x)=x_{\left(A, \sigma_{A}\right)} \frac{\lambda_{A}^{\sigma_{A} \rightarrow \bar{\sigma}_{A}}(x)}{G_{A}(N)}
$$

para $A \in \mathcal{P}^{*}(\mathcal{T})$ e $\sigma_{A}, \bar{\sigma}_{A} \in \mathcal{S}_{A}$. Considerando $\left(A, \sigma_{A}\right) \subseteq \mathcal{E}$ diremos que

$$
x_{\left(A, \sigma_{A}\right)}=\prod_{i \in A} x_{\left(i, \sigma_{A}(i)\right)},
$$

$\operatorname{com} x_{\left(i, \sigma_{A}(i)\right)}$ a densidade do elemento de tipo $i \in A$, no estado $\sigma_{A}(i) \in \mathcal{S}_{i}$.

Assim, vemos que o nosso processo de perfil de densidade, com propriedades de um passeio aleatório, no momento de apresentar uma transição nos tipos em $A$, desde os estados $\sigma_{A}$ para os estados $\bar{\sigma}_{A}$, terá que somar $1 / N$ em todas as coordenadas de $\left(A, \bar{\sigma}_{A}\right)$ e subtrair $1 / N$ às coordenadas de $\left(A, \sigma_{A}\right)$. De outra forma, referimo-nos a uma transição do tipo

$$
x \longrightarrow x+\frac{e_{A}^{\sigma_{A}, \bar{\sigma}_{A}}}{N}
$$

em que

$$
\left(e_{A}^{\sigma_{A}, \bar{\sigma}_{A}}\right)_{(i, b)}=\left\{\begin{aligned}
1 & \text { se } i \in A, \bar{\sigma}_{A}(i)=b \\
-1 & \text { se } i \in A, \sigma_{A}=b \\
0 & \text { se } c . c
\end{aligned}\right.
$$

Por outro lado, todo processo microscópico $\left\{\eta_{t}\right\}_{t \geq 0} \in \Sigma$ define um processo de perfil de densidade $w_{t}^{m\left(\eta^{0}\right), N}=m\left(\eta_{t}\right)$. Destaca-se que em um sistema microscópico na configuração $\eta=\eta_{\left(A, n_{A}\right)}^{\sigma_{A}}$, tal que a sua densidade empírica $m(\eta)=x$, no momento de encontrar uma transição de $\eta$ para $\eta_{\left(A, n_{A}\right)}^{\bar{\sigma}_{A}}$, observamos uma transição do tipo (2.37) no perfil de densidade associado. Logo, definimos a seguinte relação,

$$
\lambda_{A}^{\sigma_{A} \rightarrow \bar{\sigma}_{A}}(x)=\frac{\Theta_{A}^{\sigma_{A} \rightarrow \bar{\sigma}_{A}}(m(\eta))}{N^{|A|}} .
$$

Isto é, cada $\lambda_{A}^{\sigma_{A} \rightarrow \bar{\sigma}_{A}}$ representa a taxa com que um vetor específico de sítios $\left(A, n_{A}\right)$ troca os seus estados internos de $\sigma_{A}$ para $\bar{\sigma}_{A}$. Portanto, para representar a taxa referente a $(2.37)$ consideramos 
uma configuração $\eta \in \Sigma$ tal que a sua densidade empírica $m(\eta)=x$. Deste modo

$$
\left.\frac{d}{d t} P\left(w_{t}^{x, N}=x+\frac{e_{A}^{\sigma_{A}, \bar{\sigma}_{A}}}{N}\right)\right|_{t=0}=\sum_{\substack{n_{A} \in \Lambda^{|A|} \\ \eta_{\left(A, n_{A}\right)}=\sigma_{A}}} c\left(\eta_{\left(A, n_{A}\right)}^{\sigma_{A}}, \eta_{\left(A, n_{A}\right)}^{\bar{\sigma}_{A}}\right)
$$

Por definição a taxa $c\left(\eta_{\left(A, n_{A}\right)}^{\sigma_{A}}, \eta_{\left(A, n_{A}\right)}^{\bar{\sigma}_{A}}\right)$ independe do vetor $n_{A}$ que satisfaz a condição na somatoria. Assim, somente precisamos contar as formas em que o vetor $n_{A}$ pode ser escolhido em $\eta$. Logo, o número de maneiras possíveis é igual a $N^{|A|} x_{\left(A, n_{A}\right)}$ (em concordância com (2.36)).

Portanto, empregando a notação de (2.35), escrevemos

$$
N^{|A|} f_{A}^{\sigma_{A} \rightarrow \bar{\sigma}_{A}}(x)=\left.\frac{d}{d t} P\left(w_{t}^{x, N}=x+\frac{e_{A}^{\sigma_{A}, \bar{\sigma}_{A}}}{N}\right)\right|_{t=0} .
$$

Desta forma o novo drift associado ao nosso modelo, obtido da equação (2.23) e usando as propriedades dos processos de Poisson, é da forma:

$$
\begin{aligned}
V_{(i, b)}(x)= & \sum_{\substack{A \in \mathcal{P}^{*}(\mathcal{T}) \\
A \ni i}} \sum_{\substack{\sigma_{A} \in \mathcal{S}_{A} \\
\sigma_{A}(i) \neq b}} \sum_{\bar{\sigma}_{A} \in \mathcal{S}_{A}} \frac{1}{N} N^{|A|} x_{\left(A, \sigma_{A}\right)} \frac{\lambda_{A}^{\sigma_{A} \rightarrow \bar{\sigma}_{A}}(x)}{G_{A}(N)} \\
& -\sum_{\substack{A \in \mathcal{P}^{*}(\mathcal{T}) \\
A \ni i}} \sum_{\substack{\sigma_{A} \in \mathcal{S}_{A} \\
\sigma_{A}(i) \neq b}} \sum_{\substack{\bar{\sigma}_{A} \in \mathcal{S}_{A} \\
\bar{\sigma}_{A}(i)=b}} \frac{1}{N} N^{|A|} x_{\left(A, \bar{\sigma}_{A}\right)} \frac{\lambda_{A}^{\bar{\sigma}_{A} \rightarrow \sigma_{A}}(x)}{G_{A}(N)} .
\end{aligned}
$$

Conforme a ordem da função $G_{A}(N)$ poderíamos obter diferentes comportamentos do nosso processo de perfil de densidade. A seguir, analisamos três possíveis casos para propor uma escolha correta e simples para dita função, de modo que o processo esteja bem definido e no limite termodinâmico possamos obter a convergência para o sistema dinâmico correspondente.

(a) Seja $G_{A}(N)$ tal que $\forall A \in \mathcal{P}^{*}(\mathcal{T}), \frac{N^{|A|-1}}{G_{A}(N)} \stackrel{N \rightarrow \infty}{\longrightarrow} 0$. Então o processo não existe ou não tem evolução.

(b) Seja $G_{A}(N)$ tal que $\exists A \in \mathcal{P}^{*}(\mathcal{T})$ com $\frac{N^{|A|-1}}{G_{A}(N)} \stackrel{N \rightarrow \infty}{\longrightarrow} \infty$. Logo, o processo explode para tal $A \in \mathcal{P}^{*}(\mathcal{T})$.

(c) Seja $G_{A}(N)$ tal que $\forall A \in \mathcal{P}^{*}(\mathcal{T}), \frac{N^{|A|-1}}{G_{A}(N)} \stackrel{N \rightarrow \infty}{\longrightarrow} c_{A} \in \mathbb{R}$. Então o processo está bem definido $\forall A \in \mathcal{P}^{*}(\mathcal{T})$.

Por conseguinte $G_{A}(N)$ precisa ser de ordem $|A|-1$, sendo o caso mais simples a ser escolhido $G_{A}(N)=N^{|A|-1}$, o qual vamos considerar no nosso modelo. Finalmente, obtemos o drift que permite 
a convergência para o sistema dinâmico associado.

$$
V_{(i, b)}(x)=\sum_{\substack{A \in \mathcal{P}^{*}(\mathcal{T}) \\ A \ni i}} \sum_{\substack{\sigma_{A} \in \mathcal{S}_{A} \\ \sigma_{A}(i) \neq b}} \sum_{\bar{\sigma}_{A} \in \mathcal{S}_{A}} x_{\left(A, \sigma_{A}\right)} \lambda_{A}^{\sigma_{A} \rightarrow \bar{\sigma}_{A}}(x)-\sum_{\substack{A \in \mathcal{P}^{*}(\mathcal{T}) \\ A \ni i}} \sum_{\substack{\sigma_{A} \in \mathcal{S}_{A} \\ \sigma_{A}(i) \neq b}} \sum_{\bar{\sigma}_{A} \in \mathcal{S}_{A}} x_{(A, \bar{\sigma})=b} \bar{\sigma}_{A} \lambda_{A}^{\bar{\sigma}_{A} \rightarrow \sigma_{A}}(x)
$$

Como temos dito, esta última equação generaliza o drift apresentado em (2.27). Nos capítulos a seguir propomos e demonstramos o teorema de convergência associado ao nosso processo de perfil de densidade e o sistema dinâmico correspondente. 


\section{Capítulo 3}

\section{Redes de Sinalização Biológica}

Neste capítulo definimos as principais características das redes de sinalização biológica e expomos a complexidade do seu estudo. Assim, usamos os conceitos de módulos de interação para apresentar alguns exemplos que ilustram as aplicações dos modelos definidos no capítulo anterior. Na primeira seção enunciamos dois processos que podem ser modelados com os sistemas de spins com trocas simples dos estados internos, os quais foram a motivação inicial do trabalho de R. Fernández et al. [9]. Na segunda parte, mencionamos exemplos de módulos biológicos em que moléculas de tipos diferentes trocam simultaneamente os seus estados internos. Estes processos motivam a extensão dos modelos de spins estocásticos dependentes de tipo apresentada na Seção 2.3, e que permite trocas múltiplas dos spins.

\subsection{Análise multi-nível e exemplos de módulos de interação}

Para comunicar-se e responder aos sinais do ambiente, as células interagem através de sinais biológicos que são recebidos e transmitidos por meio de sequências de reações bioquímicas, que chamamos de redes de sinalização biológica quando o principal interesse é o fluxo de informação.

Estas cadeias de informação causam complexas cascatas de interações bioquímicas no interior da célula, como mostra a Figura 3.1. Uma boa referencia para entender a complexidade envolvida em uma rede de sinalização biológica é o panorama apresentado em [22], referente ao fator de crescimento epidérmico associado ao controle do crescimento, sobrevivência, proliferação e diferenciação em células mamíferas. Portanto, interpretar este tipo de redes de sinalização e entender os mecanismos de controle é um processo bastante difícil.

Contudo, o enfoque da biologia de sistemas sugere uma análise multi-nível em que o sistema é considerado em termos de uma hierarquia de módulos funcionais interconetados (ver [32]), usualmente pequenos subconjuntos de componentes que são capazes de efetuar alguma funcionalidade básica útil que contribui ao comportamento da rede de sinalização. Um exemplo disto é a capacidade de gerar oscilações que permitem processos periódicos no tempo, tais como o ritmo cardíaco 
e o ciclo celular. Outros dois exemplos de funcionalidades que poderiam ser requeridas em uma rede de sinalização são: os filtros, que permitem responder aos sinais de entrada somente quando estes estão dentro de um intervalo particular de amplitude ou frequência, e o módulo sensor de gradiente que permite a deteção de variações nas concentrações, como as requeridas para a quimiotaxia.

Desta forma, para validar a utilidade dos modelos de spins estocásticos dependentes de tipo, R. Fernández et al. [9] incluiram aplicações do modelo em alguns módulos funcionais. Nessas aplicações os spins foram pensados como representando os estados internos dos componentes do módulo de interação.

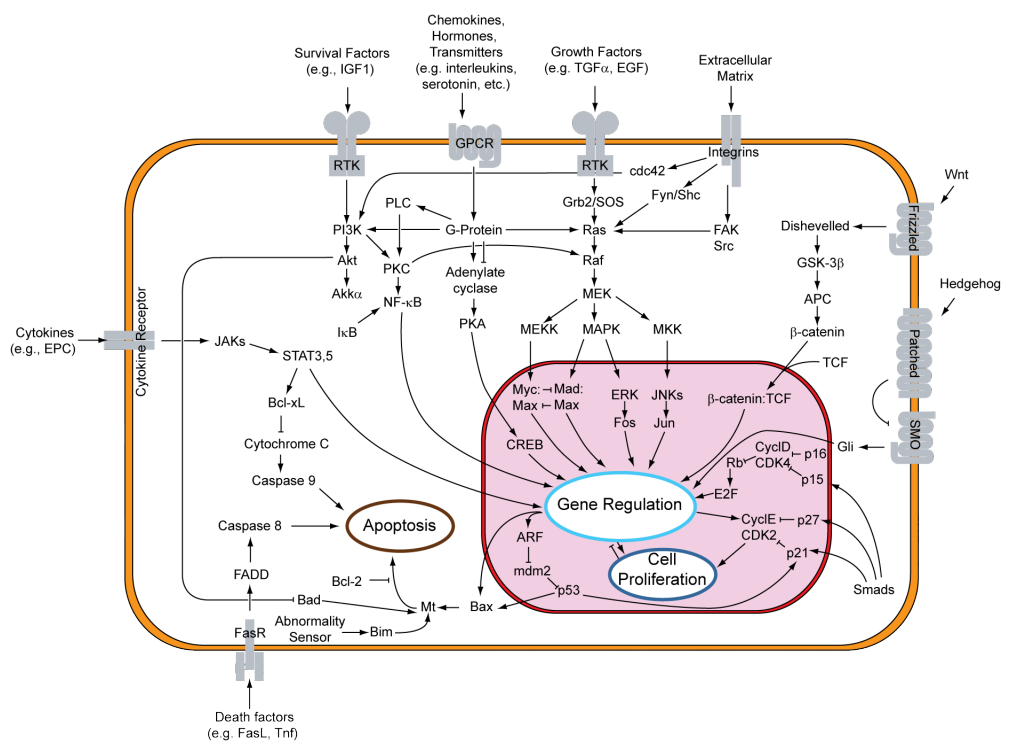

Figura 3.1: Exemplo da rede de sinalização biológica associada à decisão entre proliferação e apoptose. As setas indicam uma interação de ativação do componente bioquímico no início da seta com o componente na sua ponta; similarmente, setas sem ponta indicam inibição. Imagem obtida de [17].

A seguir fazemos uma releitura destes exemplos; apresentando primeiro a dinâmica de um sistema biológico sintético implementado in vivo em uma bactéria, que chamaremos de relógio básico; no segundo caso é analisada a estranha resposta do p53, um gene supressor tumoral envolvido na prevenção do cáncer, perante um dano no DNA.

\section{$\underline{\text { Relógio básico. }}$}

O relógio básico é o mais simples módulo de interação cíclica, o qual provê a funcionalidade básica de gerar oscilações. Tal funcionalidade é essencial para organizar funções biológicas moduladas no tempo, como por exemplo, o ajuste periódico requerido por um organismo fisiológico ao ritmo cardíaco.

Este módulo possui três componentes que chamamos de $A, B$ e $C$. Eles interagem ciclicamente 
através de uma sequência de feedback de inibição em que cada componente atua sobre o seguinte na sequência, isto é, $A$ reprime $B, B$ reprime $C$ e $C$ reprime o componente $A$ (ver Figura 3.2). Mais precisamente, a taxa de transiçao da densidade do componente $A$ a cada tempo, somente depende da densidade de $C$ em uma maneira inibitória: a densidade de $A$ tende a decrescer se a concentração de $C$ é alta. Em termos biológicos, $A$ e $C$ podem representar, por exemplo, proteínas com $C$ sendo uma enzima que acelera a taxa de degradação de $A$. Uma dependência similar existe entre $C$ e $B$ e entre $B$ e $A$. Para forças de inibição grandes, inestabilidade dinâmica pode ser esperada de modo que as concentrações dos três componentes oscilam, o qual será analisado matematicamente na Seção 4.3.

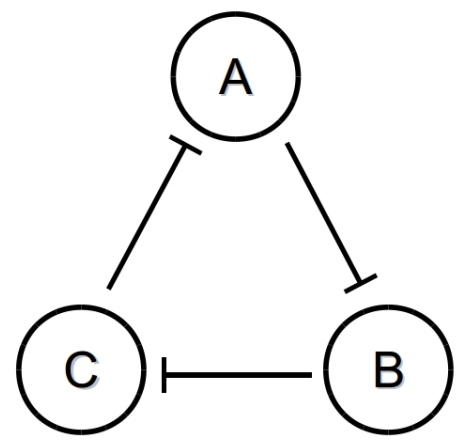

Figura 3.2: Módulo do relógio básico baseado em uma sequência de feedback de inibição entre três componentes indicados por $A, B$ e $C$. As setas sem ponta indicam inibição.

Para modelar o relógio básico supomos que os três tipos de componentes bioquímicos deste módulo interagem dentro de um contentor celular em que $N$ sítios, etiquetados desde 1 até $N$, são disponíveis para cada um dos tipos $A, B$ e $C$. Denotamos $\eta_{t}(i, n)=+1$ se no tempo $t$ há um componente do tipo $i \in\{A, B, C\}$ no sítio $n, 1 \leq n \leq N$, e no caso contrario escrevemos $\eta_{t}(i, n)=-1$. Os números $\eta_{t}(i, n)$ são pensados como spins (para acima ou para abaixo) para o tipo $i$ no sítio $n$ na notação usual da mecânica estatística. Para cada $i \in\{A, B, C\}$ denotamos por $c(i)$ o tipo do componente que o inibe, isto é, $c(A)=C, c(B)=A$ e $c(C)=B$. Assumimos que cada spin $\eta_{t}(i, n)$ troca com taxas que só dependem da densidade no tempo $t$ do componente $c(i)$. Escrevemos $\eta_{t} \in\{-1,+1\}^{\{A, B, C\} \times\{1, \ldots, N\}}$ para o espaço de configurações do sistema no tempo $t$, e denotamos por $c(i, n, \eta)$ a taxa com que o spin de tipo $i$ no sítio $n$ troca quando a configuração atual é $\eta$. Diversas escolhas das taxas de transição podem ser naturais para representar esta sequência de inibição. Uma escolha simples é dada por

$$
c(i, n, \eta)=\exp \left\{J \eta(i, n) \frac{1}{N} \sum_{l=1}^{N} \eta(c(i), l)\right\} .
$$

em que $J$ é o parâmetro que mede a força da inibição. A região $J>0$ é de interesse para imitar a sequência de inibição, com taxas resultantes que favorecem os spins de tipo $i$ ficarem opostos à maioria dos spins de tipo $c(i)$. No capítulo a seguir analisaremos os comportamentos que estes processos poderiam apresentar, baseados no resultado de convergência proposto no Teorema 4.1.1. 


\section{Módulo p53.}

O segundo exemplo biológico será chamado módulo p53. P53 é um gene supressor tumoral que codifica uma proteína que tem uma importante tarefa na manutenção da integridade genômica celular e na prevenção do câncer. Experimentos recentes [15] verificaram que com um dano no DNA obtem-se, em cada célula simples danificada, um número de pulsos de p53 que possuem essencialmente a mesma amplitude e forma, em vez de, como se espera inicialmente, oscilações amortecidas. Diversos artigos tratam este problema e tentam entender a fonte deste comportamento dinâmico através de modelos matemáticos (ver, por exemplo, [18, 24]). Particularmente, T. Zhang et al. [34], definiram quatro mecanismos simples pelos quais o p53 poderia ser regulado, e propuseram modelos matemáticos que os descrevem, isto baseado em ideias usuais da cinética química e supostos simplificados adicionais.

A Figura 3.3 mostra a interação das proteínas p53 e Mdm2, em concordância com um dos mecanismos propostos em [34]. Neste módulo foi aplicado um dano no DNA o qual ativa um feedback entre as duas moléculas. Como indica a figura, Mdm2 é uma proteína que tem a dupla tarefa de ativação/inibição com respeito ao p53: Mdm2 no citoplasma acentua a transcrição da cadeia de RNA de p53 para gerar uma proteína de p53 (quer dizer, ativando o p53) enquanto Mdm2 no núcleo medeia a degradação do p53 (ou seja, inibindo o p53). Finalmente a transcrição do Mdm2 é induzida pelo mesmo p53. Assim, três estados são necessários para descrever os diferentes papeis do Mdm2, isto é, o estado 0 indica Mdm2 não presente (ou degradado), o estado 1 para Mdm2 presente no citoplasma e o estado 2 para Mdm2 presente no núcleo. No outro caso, somente dois estados (presente/ausente) são suficientes para descrever o p53.

O conjunto das possíveis trocas de estado para cada $n \in\{1, \ldots, N\}$ é indicado na Figura 3.3. As setas sólidas indicam transições; por exemplo, a transição de Mdm2 do estado 2 para o estado 0 corresponde à degradação de uma molécula de Mdm2 que está no núcleo, enquanto a transição inversa, desde 0 para 2, não é permitida porque Mdm2 só pode ser produzida no citoplasma, pela transcrição do RNA. Setas tracejadas desde o estado de um dado componente e que terminam em uma seta sólida, indicam que a transição é regulada pela densidade associada; por exemplo, a transição em que p53 é produzido, isto é, ir do estado 0 para o estado 1, é regulada pelo Mdm2 no estado 1, quer dizer, depende da densidade do Mdm2 no citoplasma.

Desta forma propoẽ-se uma ideia intuitiva muito simples para modelar este tipo de rede: primeiro é assumido que cada transição poderia depender do perfil de densidade no sentido da representação qualitativa das possíveis interações. Logo, as equações diferenciais são formalmente obtidas das equações de Kolmogorov.

Denotamos por $x, y$ e $z$ as densidades de p53, Mdm2 no citoplasma e mdm2 no núcleo, respec- 


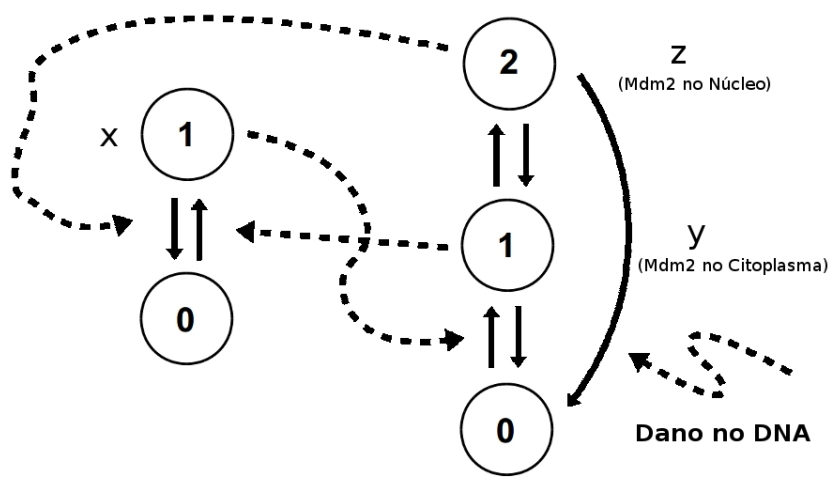

p53

Mdm2

Figura 3.3: Possiveis transições correspondentes às interações p53/Mdm2 dadas por T. Zhang et al. [34]; setas sólidas indicam transições. setas tracejadas desde um estado até uma seta sólida indicam que a taxa de transição é regulada pela densidade do estado inicial.

tivamente. As taxas que não são reguladas, por exemplo a transição correspondente à degradação de Mdm2 (do estado 1 ao estado 0) são assumidas como constantes, as quais poderão ser escolhidas pela informação bioquímica disponível, mas esses valores não serão considerados como crucialmente importantes. Isto, devido a que processos que dependem de supostos demasiado finos poderiam não ser confiáveis no ambiente celular extremadamente ruidoso.

As três taxas reguladas por alguma densidade, indicadas na Figura 3.3, são qualitativamente similares e serão escolhidas em função de equações do tipo (2.13). Por exemplo, a taxa de produção do p53 depende da densidade de Mdm2 no citoplasma de tal forma que uma alta (baixa) densidade de Mdm2 no citoplasma implica taxas de produção maiores (menores). Para representar isto assumimos que a taxa de produção de p53 é uma função crescente em y, a densidade de Mdm2 no citoplasma. Assim uma simples escolha desta função é dada por

$$
S(y, V, \alpha, a)=\frac{V}{1+e^{-\alpha(y-a)}}
$$

em que $V, \alpha$ e $a$ são parâmetros.

O processo de perfil de densidade associado é definido da seguinte maneira. Existem dois tipos, $\mathcal{T}=\{p, M\}$ (para p53 e Mdm2), com espaços internos de spins $\mathcal{S}_{p}=\{0,1\}$ e $\mathcal{S}_{M}=\{0,1,2\}$. As respectivas densidades serão denotadas por

$$
\begin{array}{ll}
x_{(M, 2)}=z, \\
x_{(p, 1)}=x, & x_{(M, 1)}=y, \\
x_{(p, 0)}=1-x, & x_{(M, 0)}=1-y-z,
\end{array}
$$


e as taxas de transição dadas por

$$
\begin{array}{ll}
\lambda_{p}^{0 \rightarrow 1}=S\left(y, V_{y x}, \alpha_{y x}, a_{y x}\right), & \lambda_{M}^{1 \rightarrow 2}=q_{12} \\
\lambda_{p}^{1 \rightarrow 0}=S\left(z, V_{z x}, \alpha_{z x}, a_{z x}\right), & \lambda_{M}^{1 \rightarrow 0}=q_{10} \\
\lambda_{M}^{0 \rightarrow 1}=S\left(x, V_{x y}, \alpha_{x y}, a_{x y}\right), & \lambda_{M}^{2 \rightarrow 1}=q_{21} \\
\lambda_{M}^{2 \rightarrow 0}=\gamma .
\end{array}
$$

Aqui $q_{i j}$ indica a taxa de transição (constante) do $\operatorname{Mdm} 2$ do estado $i$ para o estado $j$ e $S(\cdot)$ é a função definida anteriormente. O parâmetro $\gamma$ mede a entrada do sistema dinâmico, isto é, a força do dano no DNA.

As equações diferenciais resultantes para o módulo p53 são,

$$
\begin{aligned}
& \dot{x}=(1-x) S\left(y, V_{y x}, \alpha_{y x}, a_{y x}\right)-x S\left(z, V_{z x}, \alpha_{z x}, a_{z x}\right), \\
& \dot{y}=(1-y-z) S\left(x, V_{x y}, \alpha_{x y}, a_{x y}\right)-y\left(q_{12}+q_{10}\right)+z q_{21}, \\
& \dot{z}=y q_{12}-z\left(q_{21}+\gamma\right) .
\end{aligned}
$$

Quando analisado este sistema dinâmico, o principal output de interesse é a densidade do p53, dado por $x$. Uma análise de bifurcações para este modelo pode ser encontrada no trabalho de R. Fernández et al. [9], a qual apresenta uma bifurcação de Hopf subcrítica para um valor particular de $\gamma$, dito $\gamma_{c}$, tal que a concentração de p53 permanece estável para $\gamma<\gamma_{c}$, mas oscilações com grande amplitude aparecem quando $\gamma$ supera este limiar.

Para esclarecer a forma em que é feita a análise de bifurcações e apresentar outros resultados, voltaremos neste tema na Seção 4.3, na qual damos um exemplo referente ao módulo de interação cíclica.

\subsection{Módulos de interação com trocas múltiplas}

O trabalho de R. Fernández et al. [9] permite modelar módulos biológicos em que as transições nos estados internos acontecem em uma única molécula por vez. Porém, existem outros tipos de módulos de interação que ficam excluídos desta modelagem, devido ao fato de que estes processos incluem situações nas quais um grupo de moléculas de tipos diferentes trocam simultaneamente os seus estados internos.

Por exemplo, o processo proposto na Figura 3.3 poderia ser modelado de forma alternativa como representado na Figura 3.4. Agora a interação p53/mdm2 apresenta três tipos de elementos $(|\mathcal{T}|=3)$. Cada tipo possui dois estados, ou seja temos um modelo de Ising. No caso, quando uma molécula de mdm2 passa do citoplasma para o núcleo, precisamos de uma troca dupla dos spins; 
mudando um elemento do tipo $i$ (mdm2 no citoplasma) do estado 1 para o estado 0 e um elemento do tipo $j$ (mdm2 no núcleo) do estado 0 para o 1 , simultaneamente.

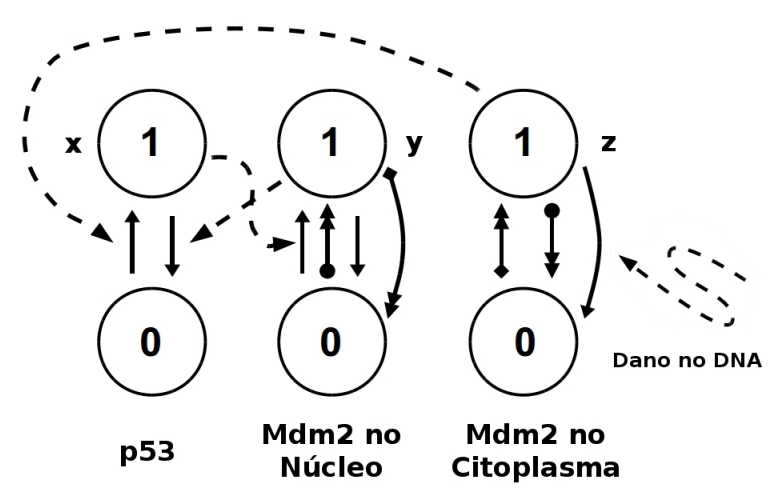

Figura 3.4: Modelo de Ising com trocas múltiplas dos spins, caracterizando a mesma interação da Figura 3.3. Setas duplas identificam transições duplas; a seta dupla com um ponto no início representa o passo de uma molécula de mdm2 do citoplasma para o núcleo, enquanto a seta com um diamante no início representa o trajeto inverso.

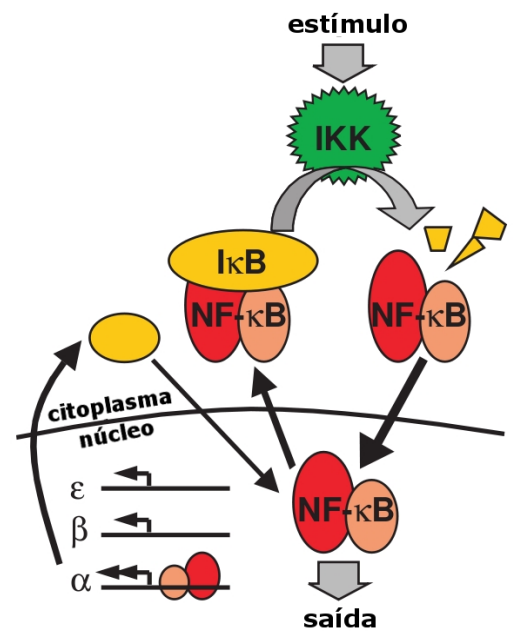

Figura 3.5: $O$ módulo de sinalização I $\beta-N F-\kappa B$ de A. Hoffmann et al. [12]. NF- $\kappa B$ é segurado inativo no citoplasma pelos

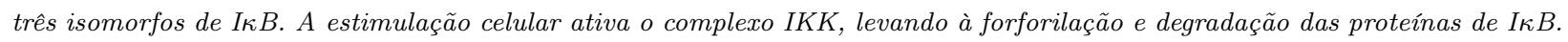
$O N F-\kappa B$ liberado é conduzido ao núcleo, ativando genes, incluindo o I $\kappa B \alpha$. I $\beta \beta$ e $-\varepsilon$ são sintetizados com taxas constantes, permitindo um complexo controle temporal da ativação de $N F-\kappa B$, envolvendo um feedback negativo.

Entretanto, um outro processo que pode ser modelado considerando trocas múltiplas dos spins é representado na Figura 3.5. O fator de transcrição NF- $\kappa$ B é um importante mediador inflamatório, o qual é essencial na maioria dos eventos de indução de genes em resposta à citocina inflamatória e às substâncias derivadas dos agentes infecciosos. A regulação do NF- $\kappa$ B é importante no estudo da fisiologia da ativação da inflamação ou a imunidade a ela. Além disso, a incorreta regulação da ativação do NF- $\kappa$ B tem sido identificada como o principal culpado de doenças inflamatórias crônicas e câncer.

Em células desestimuladas, $\mathrm{NF}-\kappa \mathrm{B}$ é amarrado às proteínas de $\mathrm{I} \kappa \mathrm{B}$, o seu inibidor, que o mantém 
inativo no citoplasma. Mas, estimulações celulares com agentes inflamatórios produzem a fosforilação do $\mathrm{I} \kappa \mathrm{B}$ e a sua consequente degradação, através da quinase chamada IKK. Isto permite que o $\mathrm{NF}-\kappa \mathrm{B}$ liberado seja acumulado no núcleo, ajudando na produção de novas moléculas de $\mathrm{I} \kappa \mathrm{B}(\mathrm{R}$. Cheong et al. [3]). É importante salientar que somente o NF- $\kappa$ B liberado é importado ao interior do núcleo, transição que requer da degradação da molécula de $\mathrm{I} \kappa \mathrm{B}$ associada. Em contraste, desde o interior do núcleo, somente o complexo formado por $\mathrm{NF}-\kappa \mathrm{B}$ e I $\kappa \mathrm{B}$ pode ser transportado ao citoplasma, ambas as situações implicam uma transição dupla dos estados internos.

Como mostram estes dois exemplos, as principais motivações de estender os modelos de spins estocásticos dependentes de tipo, foram representar situações nas quais varias moléculas de tipos diferentes trocam os seus estados internos simultaneamente. Além disso, os comportamentos dinâmicos destes processos tem sido estudados por varios autores, devido às interessantes respostas perante os estímulos externos. Um exemplo disso é o trabalho de S. Krishna et al. [14], em que obtem-se um modelo mínimo para gerar o mesmo tipo de oscilações achadas no módulo de sinalização associado a NF- $\kappa \mathrm{B}$. 


\section{Capítulo 4}

\section{Principais Resultados}

Neste capítulo enunciamos os principais resultados referentes aos processos estocásticos dependentes de tipo e à modelagem das redes de sinalização biológica. Desta forma incluímos: o teorema principal dado em [9]; o nosso resultado mais importante, sendo uma extensão deste último; e uma nova análise de bifurcações, com um resultado próprio sobre o comportamento do sistema dinâmico associado a um módulo de interação cíclica, que chamaremos de relógio básico assimétrico.

\subsection{Teorema de convergência para $\left(m_{t}^{x^{0}, N}\right)_{N}$}

O principal resultado dado por R. Fernández et al. em [9], assegura que no limite termodinâmico e para um intervalo de tempo finito, as trajetórias dos processos de perfil de densidade $\left(m_{t}^{x^{0}, N}\right)_{N}$ convergem quase certamente para as trajetórias determinísticas dadas pelos sistemas dinâmicos associados. Para estabelecer tal resultado precisamos definir o tempo de parada $\tau_{\epsilon}^{N}$, dado por:

$$
\tau_{\epsilon}^{N}=\inf \left\{t \geq 0:\left|m_{t}^{x^{0}, N}-x_{t}^{x^{0}}\right|>\frac{1}{N^{1 / 2-\epsilon}}\right\}
$$

com,

$$
|x|=\sum_{l=1}^{N} \sum_{\underline{i} \in \mathcal{E}}\left|x_{(\underline{i}, l)}\right| .
$$

Além disso, para um dado $T, 0 \leq T<\infty$, seja o evento:

$$
\mathcal{A}_{N \epsilon}^{T}=\left\{\tau_{\epsilon}^{N}<T\right\}
$$

Logo, segue o teorema. 
Teorema 4.1.1. Sejam $\lambda_{i}^{a \rightarrow b}, a, b \in S_{i}, i \in \mathcal{T}$ funçôes limitadas de $\mathbb{R}^{\mathcal{E}}$ a $\mathbb{R}_{+}$, que satisfazem $a$ condição de Lipschitz

$$
\left|\lambda_{i}^{a \rightarrow b}(x)-\lambda_{i}^{a \rightarrow b}(y)\right| \leq K|x-y|,
$$

para algum $K>0$, todo $x, y \in[0,1]^{\mathcal{E}}$ e todo $i \in \mathcal{T}$ e a,b $\in \mathcal{S}_{i}$. Então, para algum $T$ finito, posição inicial $x^{0} \in \mathcal{H}_{\mathcal{E}}$ e $\epsilon>0$

$$
P\left(\overline{\lim }_{N} \mathcal{A}_{N \epsilon}^{T}\right)=0 .
$$

Isto é, para realizações típicas, existe algum $N_{\epsilon, T}$ tal que para $N>N_{\epsilon, T}$ cada processo $\left\{m_{t}^{x^{0}, N}\right\}_{t \geq 0}$ mantém-se à distância $N^{-1 / 2+\epsilon}$ da trajetória determinística $\left\{x_{t}^{x^{0}}\right\}_{t \geq 0}$ ao menos até o tempo $T$.

Cabe mencionar que este resultado tem permitido estudar o comportamento das redes de sinalização através da evolução determinística do sistema dinâmico, objetivo proposto pelos autores de [9], o qual passamos a revisar na Seção 4.3.

\subsection{Teorema de convergência para $\left(w_{t}^{x^{0}, N}\right)_{N}$}

Consideramos o processo de perfil de densidade $\left\{w_{t}^{x^{0}, N}\right\}_{t \geq 0}$ em $\mathcal{D}_{N}$ definido na Subseção 2.3.2; com o seu drift adjunto dado por (2.43). Definimos $\left\{x_{t}^{x^{0}}\right\}_{t \geq 0}$ como sendo a solução do novo sistema dinâmico associado

$$
\dot{x}_{t}=V\left(x_{t}\right) .
$$

Dado o conjunto de estados iniciais $\mathcal{H}_{\mathcal{E}}$ definido em (2.22), e o novo tempo de parada $\tau_{\epsilon}^{N}$, com:

$$
\tau_{\epsilon}^{N}=\inf \left\{t \geq 0:\left|w_{t}^{x^{0}, N}-x_{t}^{x^{0}}\right|>\frac{1}{N^{1 / 2-\epsilon}}\right\}
$$

Seja também o seguinte evento, definido para $T, 0 \leq T<\infty$

$$
\mathcal{A}_{N \epsilon}^{T}=\left\{\tau_{\epsilon}^{N}<T\right\}
$$

Segue o nosso principal resultado.

Teorema 4.2.1. Sejam $\lambda_{A}^{\sigma_{A} \rightarrow \bar{\sigma}_{A}}$, com $\sigma_{A}, \bar{\sigma}_{A} \in \mathcal{S}_{A}, A \in \mathcal{P}^{*}(\mathcal{T})$ funções limitadas de $\mathbb{R}^{\mathcal{E}}$ a $\mathbb{R}_{+}$, que satisfazem a condição de Lipschitz

$$
\left|\lambda_{A}^{\sigma_{A} \rightarrow \bar{\sigma}_{A}}(x)-\lambda_{A}^{\sigma_{A} \rightarrow \bar{\sigma}_{A}}(y)\right| \leq K|x-y|
$$

para algum $K>0$, todo $x, y \in[0,1]^{\mathcal{E}}$ e todo $A \in \mathcal{P}^{*}(\mathcal{T})$ e $\sigma_{A}, \bar{\sigma}_{A} \in \mathcal{S}_{A}$. Então, para algum $T$ finito, posição inicial $x^{0} \in \mathcal{H}_{\mathcal{E}}$ e $\epsilon>0$

$$
P\left(\overline{\lim }_{N} \mathcal{A}_{N \epsilon}^{T}\right)=0
$$


Novamente dizemos que para realizações típicas, existe algum $N_{\epsilon, T}$ tal que para $N>N_{\epsilon, T}$ cada processo $\left\{w_{t}^{x^{0}, N}\right\}_{t \geq 0}$ mantém-se à distância $N^{-1 / 2+\epsilon}$ da trajetória determinística $\left\{x_{t}^{x^{0}}\right\}_{t \geq 0}$ ao menos até o tempo $T$.

Com este resultado podemos dizer que o modelo proposto por R. Fernández et al. [9] pode ser usado de forma mais geral, permitindo agora trocas múltiplas dos spins. Este processo mantém as propriedades já estabelecidas por eles e apresenta-se como uma nova ferramenta para o estudo de redes de sinalização biológica de diversa complexidade.

\subsection{Análise de bifurcações para o módulo de interação cíclica}

Utilizamos o resultado enunciado no Teorema 4.1.1, para analisar o comportamento dos sistemas dinâmicos provenientes da modelagem de módulos de interação cíclica através dos modelos de spins estocástico. Lembramos que tais módulos são representados por sistemas de partículas com trocas de spins individuais, sendo o principal exemplo destes o relógio básico caracterizado na Seção 3.1.

O módulo de interação cíclica será representado por um modelo de Ising estocástico definido através de uma simples escolha dos parâmetros na equação (2.16), os quais não obstante conduzem a interessantes comportamentos dinâmicos (determinísticos) no limite termodinâmico. Para analisar estes modelos pensamos os tipos de spins como pontos $\{1, \ldots, k\}$ sobre o círculo e, para cada $i \in \mathcal{T}$, denotamos $h(i)$ o vizinho mais próximo no sentido horario e $a(i)$ sendo o vizinho mais próximo no sentido anti-horario. Assumimos que as interações entre os tipos são definidas por,

$$
\alpha_{i, j}=\left\{\begin{aligned}
s_{i} \delta J & \text { se } j=h(i) \\
s_{j}(1-\delta) J & \text { se } j=a(i) \\
0 & \text { caso contrario }
\end{aligned}\right.
$$

em que $s_{i} \in\{-1,1\}, J>0$ e $\delta \in[0,1]$. No caso do relógio básico da Figura 3.2, vemos que $\delta=1$ e $s_{i}=-1, \forall i \in\{A, B, C\}$. É importante salientar que para os diferentes valores de $\delta$ existe uma assimétria nas interações entre cada par de tipos vizinhos. Um exemplo da situação assimétrica é dado na Figura 4.1.

No momento de descrever o processo de perfil de densidade do tipo Ising, denotamos $x(i, 1)=x_{i}$ e $x(i,-1)=1-x_{i}$. Logo, para as taxas definidas em (2.10) usamos a função $\Phi$ dada em (2.12). 


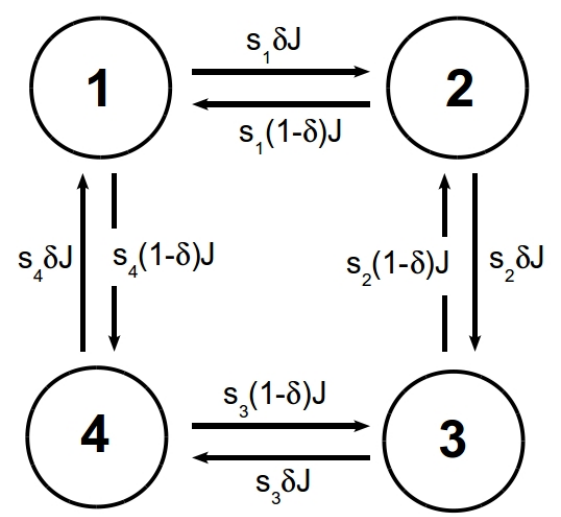

Figura 4.1: Exemplo de interação assimétrica de quatro componentes. Neste caso, as setas representam uma interação genérica. Porém, conhecendo os valores de $s_{i}$ elas teriam de representar produção ou inibição.

Assim, obtemos as taxas associadas definidas por

$$
\begin{aligned}
& \lambda_{i}^{-1 \rightarrow 1}=\exp \left(\sum_{j \in \mathcal{T}} \alpha_{j, i} x_{j}+h_{i}\right) \mathrm{e} \\
& \lambda_{i}^{1 \rightarrow-1}=\exp \left(-\sum_{j \in \mathcal{T}} \alpha_{j, i} x_{j}-h_{i}\right) .
\end{aligned}
$$

em que $\alpha_{j, i}$ e $h_{i}$ são números reais para $i, j \in \mathcal{T}$. Logo, usando o resultado do Teorema 4.1.1, o sistema dinâmico associado ao modelo de interação cíclica definido em (4.11) e com taxas dadas por (4.12) será

$$
\dot{x}_{i}=\left(1-x_{i}\right) e^{s_{a(i)} \delta J x_{a(i)}+s_{i}(1-\delta) J x_{h(i)}+h_{i}}-x_{1} e^{-s_{a(i)} \delta J x_{a(i)}-s_{i}(1-\delta) J x_{h(i)}-h_{i}},
$$

para $1 \leq i \leq k$.

Dada a natureza não linear deste sistema dinâmico é preciso utilizar a ferramenta de linearização em torno de um ponto de equilibrio. A seguir, apresentamos uma breve definição desta ferramenta (ver, para mais detalhes, [23, 27]).

\section{Linearização.}

Seja o sistema dinâmico não linear, dado por

$$
\dot{x}=f(x), \quad x \in \mathbb{R}^{n} .
$$

Um primeiro passo para analisar este tipo de sistemas é achar um ponto de equilibrio $\bar{x} \in \mathbb{R}^{n}$, tal que $f(\bar{x})=0$. Logo, consideramos a pequena perturbação $y=x-\bar{x}$, obtendo $\dot{y}=\frac{d(x-\bar{x})}{d t}=\dot{x}=f(x)$, porque $\bar{x}$ é constante. 
Agora, usando a expansão de Taylor dizemos que

$$
f(x)=f(y+\bar{x})=f(\bar{x})+y f^{\prime}(\bar{x})+O\left(y^{2}\right),
$$

em que $O\left(y^{2}\right)$ denota um termo quadraticamente pequeno em $y$. Por definição $f(\bar{x})=0$. Logo, se $f^{\prime}(\bar{x}) \neq 0$, os termos $O\left(y^{2}\right)$ são insignificantes e podemos escrever a aproximação

$$
\dot{y} \approx y f^{\prime}(\bar{x})
$$

Assim, podemos dizer que o comportamento local do sistema não linear (4.14), perto do ponto de equilibrio $\bar{x}$, é qualitativamente determinado pelo comportamento do sistema linear

$$
\dot{y}=\mathbf{A} y, \quad y \in \mathbb{R}^{n} .
$$

Com a matriz $A=D f(\bar{x})$. Isto é,

$$
\mathbf{A}=\left(\begin{array}{ccc}
\left(\frac{\partial f_{1}}{\partial x_{1}}\right)_{\bar{x}} & \cdots & \left(\frac{\partial f_{1}}{\partial x_{n}}\right)_{\bar{x}} \\
\vdots & \ddots & \vdots \\
\left(\frac{\partial f_{n}}{\partial x_{1}}\right)_{\bar{x}} & \cdots & \left(\frac{\partial f_{n}}{\partial x_{n}}\right)_{\bar{x}}
\end{array}\right)
$$

Uma vez definida esta técnica é possível analisar a estabilidade dos pontos de equilibrio do nosso sistema (4.13). Isto, sob a análise dos autovalores da matriz associada $A$, segundo as noções de bifurcação local ([10, 31]). Desta forma, R. Fernández et al. [9] apresentaram o seguinte resultado para o caso $\delta=1$.

Teorema 4.3.1. Considere o sistema dinâmico (4.13), com $h_{i}=-s_{a(i)} J / 2$ e $\delta=1$. Para $k \geq 3$

a) Se $\prod_{i=1}^{k} s_{i}=1$, existe uma bifurcação em $J_{c}=2$ : o ponto fixo $(1 / 2, \ldots, 1 / 2) \in \mathbb{R}^{k}$, perde estabilidade e aparecem dois pontos fixos estáveis para $J>J_{c}$.

b) Se $\prod_{i=1}^{k} s_{i}=-1$, existe uma bifurcação de tipo Hopf em $J_{c}=2 / \cos (\pi / k)$.

Por exemplo, para o relógio básico dado na Figura 3.2, em que $k=3$ e todas as interações são negativas $\left(s_{i}=-1\right.$, para $\left.i=1,2,3\right)$, o sistema dinâmico possui órbita estável para $J>J_{c}=4$. Assim, o Teorema 4.1.1 implica que, em um intervalo de tempo finito, o processo de perfil de densidade estocástico evolui perto da órbita determinística, para $N$ suficientemente grande. 
Agora apresentamos o resultado da nossa análise de bifurcações para dois casos particulares do relógio básico assimétrico.

Proposição 4.3.2. Considere o sistema dinâmico (4.13), com $\delta \in[0,1 / 2) \cup(1 / 2,1]$ e $k=3$

a) Se $s_{i}=1, \forall i \in \mathcal{T}$ e $h_{i}=-J / 2$, existe uma bifurcação em $J_{c}=2$ : o ponto fixo $(1 / 2, \ldots, 1 / 2)$ perde estabilidade e aparecem dois pontos fixos estáveis para $J>J_{c}$.

b) Se $s_{i}=-1, \forall i \in \mathcal{T}$ e $h_{i}=J / 2$, existe uma bifurcação de tipo Hopf em $J_{c}=4$.

Considerando a nomenclatura usada em mecânica estatística, se $s_{i}=1, \forall i \in \mathcal{T}$, dizemos que todas interações entre os diferentes tipos de spins são chamadas ferromagnéticas. No contexto bioquímico, isto significa que, por exemplo, o componente de tipo $a(i)$ ativa a produção do componente $i$. No outro caso, se $s_{i}=-1, \forall i \in \mathcal{T}$ as interações entre os tipos de spins serão ditas antiferromagnéticas. Em termos bioquímicos, o componente de tipo $i$ inibe a produção dos seus vizinhos, os componentes de tipo $a(i)$ e $h(i)$.

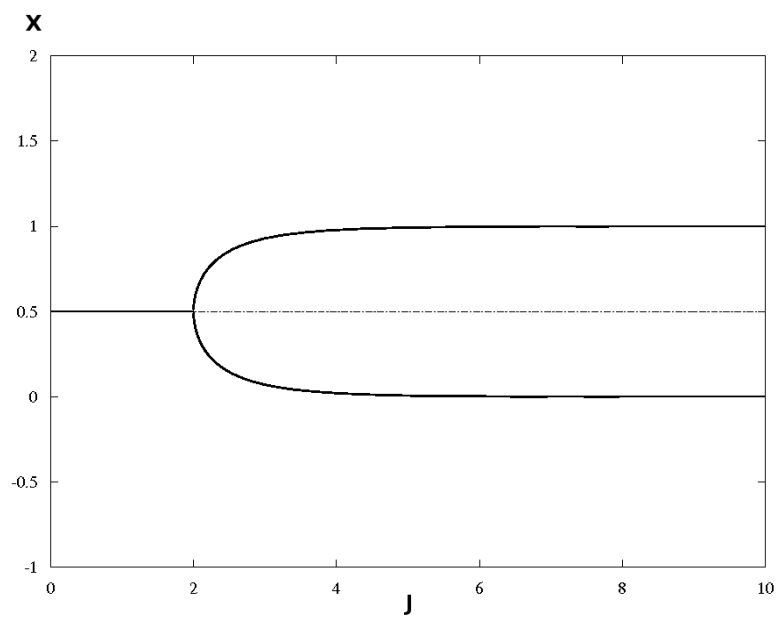

Figura 4.2: Diagrama de bifurcação para o relógio básico assimétrico ferromagnético, com $\delta=0.3$. As linhas sólidas representam pontos estáveis; linhas tracejadas indicam pontos inestáveis. Diagrama obtido com xppaut [7].

A primeira parte deste resultado, para o que chamamos de relógio básico assimétrico com interações ferromagnéticas, é representado na Figura 4.2. No caso do segundo modelo, com interações antiferromagnéticas, para os valores de $J<J_{c}=4$ a concentração do componente $x_{i}(i \in\{1,2,3\})$ permanece estável, mas oscilações com grande amplitude aparecem quando $J$ supera este limiar. O resultado é apresentado na Figura 4.3.

Concluindo diremos que, se $J$ é pequeno o sistema possui $(1 / 2,1 / 2,1 / 2)$ como o único ponto de equilíbrio estável, sem importar os sinais para $s_{i}, i \in \mathcal{T}$. Para $J$ maiores, o comportamento do sistema dinâmico depende principalmente dos valores escolhidos para os $s_{i}$. Com $s_{i}=1, \forall i \in\{1,2,3\}$ 


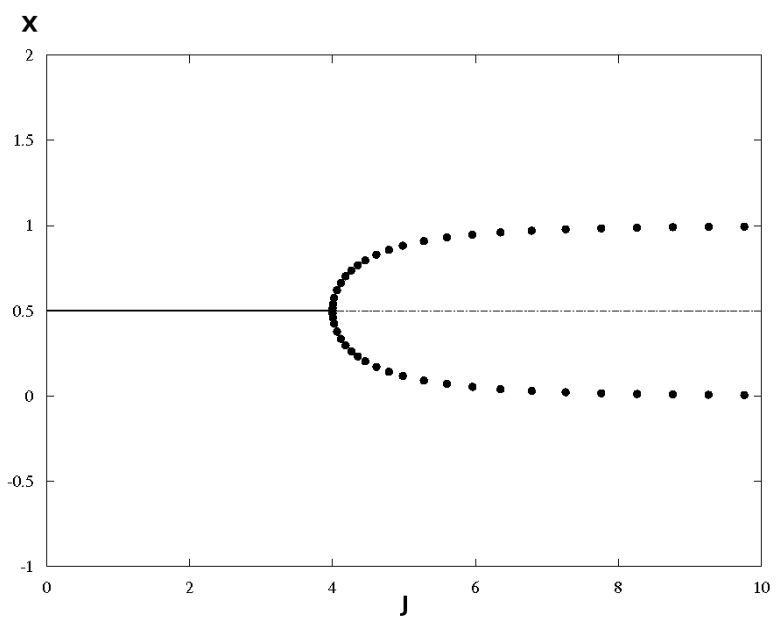

Figura 4.3: Diagrama de bifurcação para o relógio básico assimétrico antiferromagnético, com $\delta=0.1$. Vemos a bifurcação de tipo Hopf com respeito ao parâmetro J, que mede a força da interação. Linhas sólidas representam pontos estáveis; linhas tracejadas indicam pontos inestáveis; pontos pretos indicam valores máximos e mínimos das órbitas estáveis. Diagrama realizado com xppaut [7].

o sistema comporta-se como um modelo Curie-Weiss. Por outro lado, se $s_{i}=-1, \forall i \in\{1,2,3\}$, um modelo frustrado em termos de mecânica estatística, não existe um perfil de densidade global em que todos os pares de tipos de spins minimizam a interação mútua; isto é representado na bifurcação de tipo Hopf. 


\section{Capítulo 5}

\section{Demonstrações}

Apresentamos as demonstrações dos resultados enunciados no capítulo anterior, excluindo a prova do Teorema 4.1.1 que pode ser consultado em [9]. Para demonstrar o nosso principal resultado temos usado técnicas similares às empregadas em tal artigo, tais como acoplamento e grandes desvíos (ver, por exemplo, [5, 16, 29]). No estudo dos comportamentos dos sitemas dinâmicos, utilizamos a ferramenta de linearização em torno de um ponto de equilíbrio e examinamos a estabilidade sob a análise dos autovalores da matriz associada.

\subsection{Prova do Teorema 4.2.1}

Para esta finalidade, incluímos um processo estocástico auxiliar e provamos três lemas que completam a demonstração do teorema. Estes comparam o comportamento do processo auxiliar com o sistema dinâmico associado, o que é caracterizado no Lema 5.1.1. Logo, baseado nas construções gráficas dos processos estocásticos é definido um processo de discrepâncias; a análise deste e o controle das suas taxas, descritos no Lema 5.1.2 e o Lema 5.1.3, concluem a prova.

\subsubsection{O processo auxiliar}

Construímos um processo auxiliar com as seguintes características: as taxas de transição dos estados internos dos spins serão dependentes do tempo e dadas em função da trajetória determinística de $\left\{x_{t}^{x^{0}}\right\}_{t \geq 0}$; por outro lado, a distribuição inicial com a qual são escolhidos os sítios de cada tipo, será multinomial com parâmetros dados pelo sistema dinâmico associado. O processo de perfil de densidade associado será denotado de $\left\{\widehat{w}_{t}^{B\left(x^{0}\right), N}\right\}_{t \geq 0}$.

Assim, para cada $t \geq 0, \eta_{t} \in \Sigma=\prod_{i \in \mathcal{T}} \mathcal{S}_{i}^{\Lambda}$ denota os estados internos para cada tipo $i \in \mathcal{T}$ e cada sítio $n \in \Lambda$ no tempo $t$. A sua evolução será definida da mesma forma que o processo microscópico na Seção 2.3.1, associando processos de Poisson para cada trio $\left(A, \sigma_{A}, \bar{\sigma}_{A}\right)$, que serão aceitos com probabilidades análogas a (2.31) e os sítios escolhidos da mesma forma que (2.33). 
Porém a taxa dada por (2.29) será re-definida por

$$
\frac{\Theta_{A}^{\sigma_{A} \rightarrow \bar{\sigma}_{A}}\left(x_{t}^{x^{0}}\right)}{G_{A}(N)}
$$

sendo $\left\{x_{t}^{x^{0}}\right\}_{t \geq 0}$ as soluções do sistema dinâmico (4.6) desde a posição inicial $x^{0}$. Os estados para cada sítio serão inicialmente escolhidos de maneira independente para cada par $(i, n) \in \mathcal{T} \times \Lambda$ com $P\left(\eta_{0}(i, n)=a\right)=\left(x^{0}\right)_{(i, a)}$. Como resultado, os vetores de densidade $\left[\widehat{w}_{0}^{B\left(x^{0}\right), N}(\eta)\right]_{i}$ são independentes para os diferentes tipos $i \in \mathcal{T}$, e para cada $a \in \mathcal{S}_{i}$ cada $\left[\widehat{w}_{0}^{B\left(x^{0}\right), N}(\eta)\right]_{(i, a)}$ possui uma distribuição binomial de parâmetros $N$ e $p_{(i . a)}=\left(x^{0}\right)_{(i, a)}$.

É importante identificar que para $N$ suficientemente grande, $\left\{\widehat{w}_{t}^{B\left(x^{0}\right), N}\right\}_{t \geq 0}$ começa em uma posição aleatória dentro de $\mathcal{H}_{\varepsilon}$, que chamaremos de $\widehat{x}^{0}$, a qual é próxima de $x^{0}$. Desta forma, denotaremos

$$
\left|\widehat{w}_{0}^{B\left(x^{0}\right), N}-x^{0}\right|=\frac{d}{N}
$$

Dada a permutabilidade na escolha da configuração inicial, $P\left(\eta_{0}\left(A, n_{A}\right)=\sigma_{A}\right)=P\left(\eta_{0}\left(A, \bar{n}_{A}\right)=\right.$ $\left.\sigma_{A}\right), \forall n_{A}, \bar{n}_{A} \in \Lambda^{|A|}$, e podemos assegurar que $P\left(\eta_{t}\left(A, n_{A}\right)=\sigma_{A}\right)=P\left(\eta_{t}\left(A, \bar{n}_{A}\right)=\sigma_{A}\right)$.

Logo, podemos obter as equações de Kolmogorov. Definindo $p_{t}^{n}(i, b)=P\left(\eta_{t}(i, n)=b\right)$

$$
\begin{aligned}
\dot{p}_{t}^{n}(i, b)= & \sum_{\substack{A \in \mathcal{P}^{*}(\mathcal{T}) \\
A \ni i}} \sum_{\substack{\sigma_{A} \in \mathcal{S}_{A} \\
\sigma_{A}(i) \neq b}} \sum_{\bar{\sigma}_{A} \in \mathcal{S}_{A}} p_{t}^{n_{A}}\left(A, \sigma_{A}\right) \lambda_{A}^{\sigma_{A} \rightarrow \bar{\sigma}_{A}}\left(x_{t}^{x^{0}}\right) \\
& -\sum_{\substack{A \in \mathcal{P}^{*}(\mathcal{T}) \\
A \ni i}} \sum_{\substack{\sigma_{A} \in \mathcal{S}_{A} \\
\sigma_{A}(i) \neq b}} \sum_{\bar{\sigma}_{A} \in \mathcal{S}_{A}} p_{t}^{n_{A}}\left(A, \bar{\sigma}_{A}\right) \lambda_{A}^{\bar{\sigma}_{A} \rightarrow \sigma_{A}}\left(x_{t}^{x^{0}}\right)
\end{aligned}
$$

Portanto cada função $t \rightarrow p_{t}^{n}(\underline{i})$ é uma solução da equação diferencial (4.6) com $V$ como em (2.43). Finalmente,

$$
p_{0}^{n}(\underline{i})=\left(x^{0}\right)_{\underline{i}} \Longrightarrow p_{t}^{n}(\underline{i})=\left(x_{t}^{x_{0}}\right)_{\underline{i}} \forall t \geq 0
$$

para todo $\underline{i} \in \mathcal{E}$ e $n \in \Lambda$. Insinuando que o processo auxiliar e o sistema dinâmico poderiam ter um comportamento similar. Formalmente, o lema a seguir prova que o percurso da densidade empírica $\left\{\widehat{w}_{t}^{B\left(x^{0}\right), N}\right\}$ permanece, o tempo todo, próximo da trajetória do sistema dinâmico $\left\{x_{t}^{x^{0}}\right\}$.

Lema 5.1.1. Para $\delta>0$ existe $c>0$, tal que

$$
P\left(\left|\widehat{w}_{t}^{B\left(x^{0}\right), N}-x_{t}^{x^{0}}\right|>\frac{1}{2} N^{\delta-1 / 2}\right)<\exp \left(-c N^{\delta}\right)
$$

para $t \geq 0$. 
Demonstração. Um fato importante para este processo é que a proporção esperada de spins de cada tipo, possuindo cada estado interno, coincidem com as componentes de $x_{t}^{x^{0}}$. Isto é, $E\left[\left(\widehat{w}_{t}^{B\left(x^{0}\right), N}\right)_{\underline{i}}\right]=$ $\left(x_{t}^{x^{0}}\right)_{\underline{i}}$, o qual deriva diretamente da equação de Kolmogorov. Logo, $N \widehat{w}_{t}^{B\left(x^{0}\right), N}$ pode ser representada como uma matriz $N\left(\widehat{w}_{t}^{B\left(x^{0}\right), N}\right)_{i \in \mathcal{T}}$ de vetores multinomiais independentes

$$
N\left(\widehat{w}_{t}^{B\left(x^{0}\right), N}\right)_{i} \sim \operatorname{Multi}\left(N,\left(x_{t}^{x^{0}}\right)_{i}\right)
$$

para $t \geq 0$ e $i \in \mathcal{T}$, em que $\left(x_{t}^{x^{0}}\right)_{i}=\left(\left(x_{t}^{x^{0}}\right)_{i, a}\right)_{a \in \mathcal{S}_{i}}$. Deste modo, cada coordenada de cada vetor é uma variável aleatória com distribuição binomial, ou seja:

$$
N\left(\widehat{w}_{t}^{B\left(x^{0}\right), N}\right)_{\underline{i}} \sim \operatorname{Bin}\left(N,\left(x_{t}^{x^{0}}\right)_{\underline{i}}\right)
$$

para cada $t \geq 0$ e $\underline{i} \in \mathcal{E}$. Particularmente a variância do processo $\left(\widehat{w}_{t}^{B\left(x^{0}\right), N}\right)_{\underline{i}}$ é uniformemente majorada por $1 / N$.

Logo, as propriedades de grandes desvíos da distribuição binomial, estudadas em [5], implicam que para qualquer $\delta>0$ existe uma constante $c$ tal que,

$$
P\left(\left|\widehat{w}_{t}^{B\left(x^{0}\right), N}-x_{t}^{x^{0}}\right|>\frac{1}{2} N^{\delta-1 / 2}\right)<\exp \left(-c N^{\delta}\right)
$$

para qualquer $t \geq 0$.

Tendo no lema recém-provado uma relação entre o processo auxiliar e o sistema dinâmico, a seguir iremos provar, que para $N$ suficientemente grande, os processos $\left\{w_{t}^{x^{0}, N}\right\}_{t \geq 0}$ e $\left\{\widehat{w}_{t}^{B\left(x^{0}\right), N}\right\}_{t \geq 0}$ permancem próximos em um intervalo de tempo finito. Este fato será corroborado através de um acoplamento das evoluções estocásticas, para aquilo procuramos a ajuda das construções gráficas correspondentes.

\subsubsection{Processo de discrepância e acoplamento principal}

Vamos usar, para diferentes valores de $N$, as construções gráficas $\left\{\mathrm{g}_{t}^{x^{0}, N}\right\}_{t \geq 0}$ e $\left\{\widehat{\mathrm{g}}_{t}^{B\left(x^{0}\right), N}\right\}_{t \geq 0}$, que possuem uma re-escalação do tempo referido a $\left\{w_{t}^{x^{0}, N}\right\}_{t \geq 0}$ e $\left\{\widehat{w}_{t}^{B\left(x^{0}\right), N}\right\}_{t \geq 0}$, respectivamente. Tais construções serão definidas como trajetórias em $\mathcal{D}_{N}$ determinadas por marcas de processos de Poisson.

Para cada $y \in \mathcal{D}_{N}$, associamos $\sum_{A \in \mathcal{P}^{*}(\mathcal{T})} \prod_{i \in A}\left|\mathcal{S}_{i}\right|\left(\left|\mathcal{S}_{i}\right|-1\right)$ processos de Poisson independentes: $N_{t}^{A, \sigma_{A} \rightarrow \bar{\sigma}_{A}}(y), A \in \mathcal{P}^{*}(\mathcal{T}), \sigma_{A}, \bar{\sigma}_{A} \in \mathcal{S}_{i}, \sigma_{A} \neq \bar{\sigma}_{A}$. Para o processo $\left\{\mathrm{g}_{t}^{x^{0}, N}\right\}_{t \geq 0}$ as taxas são dadas por $y_{\left(A, \sigma_{A}\right)} \lambda_{A}^{\sigma_{A} \rightarrow \bar{\sigma}_{A}}(y)$, e para $\left\{\widehat{\mathrm{g}}_{t}^{B\left(x^{0}\right), N}\right\}_{t \geq 0}$ damos taxas $y_{\left(A, \sigma_{A}\right)} \lambda_{A}^{\sigma_{A} \rightarrow \bar{\sigma}_{A}}\left(x_{t / N}^{x^{0}}\right)$, com $x_{t / N}^{x^{0}}$ a solução do sistema dinâmico associado na escala de tempo apropriada. Assim, relacionamos um tipo 
de marca particular para cada tipo de processo de Poisson. Porém, nas duas construções, uma marca do processo $N_{t}^{A, \sigma_{A} \rightarrow \bar{\sigma}_{A}}(y)$, traz a indicação de somar $1 / N$ nas coordenadas de $\left(A, \bar{\sigma}_{A}\right)$ e subtrair a mesma quantidade nas coordenadas $\left(A, \sigma_{A}\right)$. Por outro lado, lembramos que a posição inicial de $\left\{\widehat{\mathrm{g}}_{t}^{B\left(x^{0}\right), N}\right\}$ será denotada $\widehat{x}^{0}$.

Os dois processos seráo definidos por trajetórias abertas em $\mathcal{D}_{N} \times \mathbb{R}_{+}$determinadas pelas marcas. Estas curvas definidas em trechos movimentam-se ao longo do eixo de tempo positivo até uma marca dos processos de Poisson ser encontrada. Se a marca corresponde a um certo $A \in \mathcal{P}^{*}(\mathcal{T})$, nesse momento a trajetória move-se $\pm \frac{1}{N}$ em $2 \cdot|A|$ direções coordenadas de acordo com o tipo de marca. Assim, o processo $\left\{\mathrm{g}_{t}^{x^{0}, N}\right\}_{t \geq 0}$ poderá estar na posição $x$ no tempo $t$ se existe uma trajetória aberta desde $\left(x^{0}, 0\right)$ até $(x, t)$. Por outro lado, $\left\{\widehat{\mathrm{g}}_{t}^{B\left(x^{0}\right), N}\right\}_{t \geq 0}$ poderá encontrar-se na posição $x$ no tempo $t$ se existir uma trajetória aberta desde $\left(\widehat{x}^{0}, 0\right)$ até $(x, t)$.

Podemos ver que as evoluções $\left\{\mathrm{g}_{t}^{x^{0}, N}\right\}_{t \geq 0}$ e $\left\{\widehat{\mathrm{g}}_{t}^{B\left(x^{0}\right), N}\right\}_{t \geq 0}$ diferem respectivamente dos processos $\left\{w_{t}^{x^{0}, N}\right\}_{t \geq 0}$ e $\left\{\widehat{w}_{t}^{B\left(x^{0}\right), N}\right\}_{t \geq 0}$ unicamente no fato destes últimos ter taxas $N$ vezes maiores. Então um processo de perfil de densidade no tempo $t$ é equivalente a uma construção gráfica no tempo $N t$,

$$
w_{t}^{x^{0}, N}=\mathrm{g}_{N t}^{x^{0}, N} \quad \text { e } \quad \widehat{w}_{t}^{B\left(x^{0}\right), N}=\widehat{\mathrm{g}}_{N t}^{B\left(x^{0}\right), N} .
$$

Deste modo as construções gráficas acima definidas serão utilizadas para produzir realizações acopladas dos processos $w_{t}^{x^{0}, N}$ e $\widehat{w}_{t}^{B\left(x^{0}\right), N}$.

Sabemos que os processos começam desde posições diferentes, que denotamos por $\mathrm{g}_{0}^{x^{0}, N}=x^{0} \mathrm{e}$ $\widehat{\mathrm{g}}_{0}^{B\left(x^{0}\right), N}=\widehat{x}^{0}=x^{0}+\Delta^{0}$. Assim, usamos um acoplamento que força ambos processos a manter a distância relativa o maior tempo possível, evoluindo como um sistema rigido. É claro, por causa das taxas não serem iguais, essas construções farão movimentos assincrônicos ocasionais que afastarão os processos analisados no decorrer do tempo. Por este motivo o acoplamento é desenhado para controlar tal assincronia.

O acoplamento envolve, para cada $A \in \mathcal{P}^{*}(\mathcal{T})$, um certo número de processos de marcas de tipo Poisson (ou marcas Poissonianas), que são atualizados cada vez que acontece um movimento assincrônico. Os sucessivos tempos destes movimentos correspondem a uma sequência de tempos de paradas $\left\{\tau_{n}\right\}_{n \geq 1}$; o acoplamento será definido de forma recursiva para os sucessivos intervalos de tempo $\left[\tau_{n-1}, \tau_{n}\right), n \geq 1$.

\section{Primeira etapa do acoplamento.}

Começamos os processos com $\mathrm{g}_{0}^{x^{0}, N}=x^{0}$ e $\widehat{\mathrm{g}}_{0}^{B\left(x^{0}\right), N}=\widehat{x}^{0}=x^{0}+\Delta^{0}$, estes evoluem juntos até o primeiro tempo de parada $\tau_{1}$ (a ser definido) com a seguinte regra: para cada $y \in \mathcal{D}_{N}$ e cada $A \in \mathcal{P}^{*}(\mathcal{T})$, definimos $4 \cdot \prod_{i \in A}\left|\mathcal{S}_{i}\right|\left(\left|\mathcal{S}_{i}\right|-1\right)$ processos de marcas Poissonianas; $\widehat{N}_{t}^{A, \sigma_{A} \rightarrow \bar{\sigma}_{A}, w}(y)$, 
$\widehat{N}_{t}^{A, \sigma_{A} \rightarrow \bar{\sigma}_{A}, \widehat{w}}(y), \widehat{E}_{t}^{A, \sigma_{A} \rightarrow \bar{\sigma}_{A}, w}(y)$ e $\widehat{E}_{t}^{A, \sigma_{A} \rightarrow \bar{\sigma}_{A}, \widehat{w}}(y), \sigma_{A} \neq \bar{\sigma}_{A}$, com respectivas taxas

$$
\begin{aligned}
& \widehat{u}_{t}^{A, \sigma_{A} \rightarrow \bar{\sigma}_{A}, w}\left(y, \Delta^{0}\right)=\min \left\{y_{\left(A, \sigma_{A}\right)} \lambda_{A}^{\sigma_{A} \rightarrow \bar{\sigma}_{A}}(y),\left(y_{\left(A, \sigma_{A}\right)}+\Delta_{\left(A, \sigma_{A}\right)}^{0}\right) \lambda_{A}^{\sigma_{A} \rightarrow \bar{\sigma}_{A}}\left(x_{t / N}^{x^{0}}\right)\right\}, \\
& \widehat{u}_{t}^{A, \sigma_{A} \rightarrow \bar{\sigma}_{A}, \widehat{w}}\left(y, \Delta^{0}\right)=\min \left\{y_{\left(A, \sigma_{A}\right)} \lambda_{A}^{\sigma_{A} \rightarrow \bar{\sigma}_{A}}\left(x_{t / N}^{x^{0}}\right),\left(y_{\left(A, \sigma_{A}\right)}-\Delta_{\left(A, \sigma_{A}\right)}^{0}\right) \lambda_{A}^{\sigma_{A} \rightarrow \bar{\sigma}_{A}}\left(y-\Delta^{0}\right)\right\}, \\
& \widehat{e}_{t}^{A, \sigma_{A} \rightarrow \bar{\sigma}_{A}, w}\left(y, \Delta^{0}\right)=y_{\left(A, \sigma_{A}\right)} \lambda_{A}^{\sigma_{A} \rightarrow \bar{\sigma}_{A}}(y)-\widehat{u}_{t}^{A, \sigma_{A} \rightarrow \bar{\sigma}_{A}, w}\left(y, \Delta^{0}\right) \quad \mathrm{e} \\
& \widehat{e}_{t}^{A, \sigma_{A} \rightarrow \bar{\sigma}_{A}, \widehat{w}}\left(y, \Delta^{0}\right)=y_{\left(A, \sigma_{A}\right)} \lambda_{A}^{\sigma_{A} \rightarrow \bar{\sigma}_{A}}\left(x_{t / N}^{x^{0}}\right)-\widehat{u}_{t}^{A, \sigma_{A} \rightarrow \bar{\sigma}_{A}, \widehat{w}}\left(y, \Delta^{0}\right) .
\end{aligned}
$$

Destacamos que $\left(y_{\left(A, \sigma_{A}\right)} \pm \Delta_{\left(A, \sigma_{A}\right)}^{0}\right)=\prod_{i \in A}\left(y_{\left(i, \sigma_{A}(i)\right)} \pm \Delta_{\left(i, \sigma_{A}(i)\right)}^{0}\right)$. Por outro lado, observamos a re-escala no tempo da trajetória determinística $\left\{x_{t}^{x^{0}}\right\}$, o que é necessário para representá-la na escala de tempo adequada à construção gráfica. Além disso, $\widehat{u}_{t}^{A, \sigma_{A} \rightarrow \bar{\sigma}_{A}, w}\left(y, \Delta^{0}\right)=\widehat{u}_{t}^{A, \sigma_{A} \rightarrow \bar{\sigma}_{A}, \widehat{w}}(y+$ $\Delta^{0}, \Delta^{0}$ ) para todo $y \in \mathcal{D}_{N}$, e todo $A \in \mathcal{P}^{*}(\mathcal{T})$, portanto

$$
\widehat{N}_{t}^{A, \sigma_{A} \rightarrow \bar{\sigma}_{A}, w}(y)=\widehat{N}_{t}^{A, \sigma_{A} \rightarrow \bar{\sigma}_{A}, \widehat{w}}\left(y+\Delta^{0}\right) .
$$

Os saltos do processo $\left\{\mathrm{g}_{t}^{x^{0}, N}\right\}$ acontecem com as marcas dadas pelos processos $\left\{\widehat{E}_{t}^{A, \sigma_{A} \rightarrow \bar{\sigma}_{A}, w}(y)\right\}$ e $\widehat{N}_{t}^{A, \sigma_{A} \rightarrow \bar{\sigma}_{A}, w}(y)$, enquanto o processo $\left\{\widehat{\mathrm{g}}_{t}^{B\left(x^{0}\right), N}\right\}$ o faz com as marcas de $\left\{\widehat{E}_{t}^{A, \sigma_{A} \rightarrow \bar{\sigma}_{A}, \widehat{w}}(y)\right\}$ e $\widehat{N}_{t}^{A, \sigma_{A} \rightarrow \bar{\sigma}_{A}, \widehat{w}}(y)$. Devido a (5.11), as marcas básicas de Poisson $\left\{\widehat{N}_{t}^{A, \sigma_{A} \rightarrow \bar{\sigma}_{A}, w}(y)\right\}$ vistas para $\left\{\mathrm{g}_{t}^{x^{0}, N}\right\}$ em uma dada posição $y \in \mathcal{D}_{N}$ coincidem com as marcas básicas $\left\{\widehat{N}_{t}^{A, \sigma_{A} \rightarrow \bar{\sigma}_{A}, \widehat{w}}(y)\right\}$ vistas para $\left\{\widehat{\mathrm{g}}_{t}^{B\left(x^{0}\right), N}\right\}$ na correspondente posição $\left(y+\Delta^{0}\right) \in \mathcal{D}_{N}$. Portanto, as duas construções gráficas evoluem rigidamente, mantendo uma separação $\Delta^{0}$, até apresentar-se a primeira discrepância, isto é, até que um dos processos responda a uma das marcas de Poisson que o outro ignora. Nesse momento não é possível continuar usando o acoplamento. Em razão disso, definimos o processo da primeira discrepância como

$$
D_{t}^{0}=\sum_{A \in \mathcal{P}^{*}(\mathcal{T})} \sum_{\substack{\sigma_{A}, \bar{\sigma}_{A} \in \mathcal{S}_{A} \\ \sigma_{A} \neq \neq \bar{\sigma}_{A}}}\left[\widehat{E}_{t}^{A, \sigma_{A} \rightarrow \bar{\sigma}_{A}, w}\left(y^{0}\right)+\widehat{E}_{t}^{A, \sigma_{A} \rightarrow \bar{\sigma}_{A}, \widehat{w}}\left(y^{0}+\Delta^{0}\right)\right]
$$

em que $y^{0}$ é a trajetória do perfil de densidade definido pela construção precedente (nível 0 ). O tempo da primeira discrepância $\tau_{1}$ é o tempo do primeiro evento deste processo.

Uma vez encontrado este primeiro sucesso, será introduzida uma nova definição de acoplamento, a qual será aplicada até o tempo da segunda discrepância $\tau_{2}$. Este processo iterativo continua até o tempo $T$ escolhido no Teorema 4.2.1. A seguir é apresentado o passo recursivo na definição de tal acoplamento. 


\section{l-ésima etapa do acoplamento.}

Supondo que a construção gráfica tem sido definida até o tempo $\tau_{l}, l \geq 1$, determinando $x^{l} \in \mathcal{D}_{N}$ e $\Delta^{l} \in\left(-1-\frac{1}{N}, 1+\frac{1}{N}\right)^{\mathcal{E}}$ tal que

$$
\mathrm{g}_{\tau_{l}}^{x^{0}, N}=x^{l}, \quad \widehat{\mathrm{g}}_{\tau_{l}}^{B\left(x^{0}\right), N}=x^{l}+\Delta^{l} .
$$

Então, $w_{\tau_{l} / N}^{x^{0}, N}=x^{l}$ e $\widehat{w}_{\tau_{l} / N}^{B\left(x^{0}\right), N}=x^{l}+\Delta^{l}$. Desde o tempo $\tau_{l}$ começamos uma nova construção gráfica, a qual define a evolução dos dois processos até aparecer a próxima discrepância no tempo $\tau_{l+1}$. Para cada $y \in \mathcal{D}_{N}$ e cada $A \in \mathcal{P}^{*}(\mathcal{T})$ definimos outros processos de marcas Poissonianas $\widehat{N}_{t}^{A, \sigma_{A} \rightarrow \bar{\sigma}_{A}, w}(y), \widehat{N}_{t}^{A, \sigma_{A} \rightarrow \bar{\sigma}_{A}, \widehat{w}}(y), \widehat{E}_{t}^{A, \sigma_{A} \rightarrow \bar{\sigma}_{A}, w}(y)$ e $\widehat{E}_{t}^{A, \sigma_{A} \rightarrow \bar{\sigma}_{A}, \widehat{w}}(y)$ com respectivas taxas,

$$
\begin{aligned}
& \widehat{u}_{t}^{A, \sigma_{A} \rightarrow \bar{\sigma}_{A}, w}\left(y, \Delta^{l}\right)=\min \left\{y_{\left(A, \sigma_{A}\right)} \lambda_{A}^{\sigma_{A} \rightarrow \bar{\sigma}_{A}}(y),\left(y_{\left(A, \sigma_{A}\right)}+\Delta_{\left(A, \sigma_{A}\right)}^{l}\right) \lambda_{A}^{\sigma_{A} \rightarrow \bar{\sigma}_{A}}\left(x_{t / N}^{x^{0}}\right)\right\}, \\
& \widehat{u}_{t}^{A, \sigma_{A} \rightarrow \bar{\sigma}_{A}, \widehat{w}}\left(y, \Delta^{l}\right)=\min \left\{y_{\left(A, \sigma_{A}\right)} \lambda_{A}^{\sigma_{A} \rightarrow \bar{\sigma}_{A}}\left(x_{t / N}^{x^{0}}\right),\left(y_{\left(A, \sigma_{A}\right)}-\Delta_{\left(A, \sigma_{A}\right)}^{l}\right) \lambda_{A}^{\sigma_{A} \rightarrow \bar{\sigma}_{A}}\left(y-\Delta^{l}\right)\right\}, \\
& \widehat{e}_{t}^{A, \sigma_{A} \rightarrow \bar{\sigma}_{A}, w}\left(y, \Delta^{l}\right)=y_{\left(A, \sigma_{A}\right)} \lambda_{A}^{\sigma_{A} \rightarrow \bar{\sigma}_{A}}(y)-\widehat{u}_{t}^{A, \sigma_{A} \rightarrow \bar{\sigma}_{A}, w}\left(y, \Delta^{l}\right) \mathrm{e} \\
& \widehat{e}_{t}^{A, \sigma_{A} \rightarrow \bar{\sigma}_{A}, \widehat{w}}\left(y, \Delta^{l}\right)=y_{\left(A, \sigma_{A}\right)} \lambda_{A}^{\sigma_{A} \rightarrow \bar{\sigma}_{A}}\left(x_{t / N}^{x^{0}}\right)-\widehat{u}_{t}^{A, \sigma_{A} \rightarrow \bar{\sigma}_{A}, \widehat{w}}\left(y, \Delta^{l}\right) .
\end{aligned}
$$

Análogo a (5.11) também verificamos que,

$$
\widehat{N}_{t}^{A, \sigma_{A} \rightarrow \bar{\sigma}_{A}, w}(y)=\widehat{N}_{t}^{A, \sigma_{A} \rightarrow \bar{\sigma}_{A}, \widehat{w}}\left(y+\Delta^{l}\right)
$$

Novamente, o processo $\left\{\mathrm{g}_{t}^{x^{0}, N}\right\}$ somente salta com as marcas dos processos $\left\{\widehat{E}_{t}^{A, \sigma_{A} \rightarrow \bar{\sigma}_{A}, w}(y)\right\}$ e $\widehat{N}_{t}^{A, \sigma_{A} \rightarrow \bar{\sigma}_{A}, w}(y)$, enquanto o processo $\left\{\widehat{\mathrm{g}}_{t}^{B\left(x^{0}\right), N}\right\}$ o faz com as marcas de $\left\{\widehat{E}_{t}^{A, \sigma_{A} \rightarrow \bar{\sigma}_{A}, \widehat{w}}(y)\right\}$ e $\widehat{N}_{t}^{A, \sigma_{A} \rightarrow \bar{\sigma}_{A}, \widehat{w}}(y)$. Portanto, as duas construções gráficas evoluem rigidamente, mantendo uma separação $\Delta^{l}$, até encontrar uma nova discrepância, quando um dos processos responda a uma das suas exclusivas marcas de Poisson. No momento dessa discrepância é definido o tempo de parada $\tau_{l+1}$, sendo o primeiro sucesso do $l$-éssimo processo de discrepância $\left\{D_{t}^{l}\right\}_{t \in\left[\tau_{l}, \infty\right)}$, que satisfaz

$$
D_{t}^{l}=\sum_{A \in \mathcal{P}^{*}(\mathcal{T})} \sum_{\substack{\sigma_{A}, \bar{\sigma}_{A} \in \mathcal{S}_{A} \\ \sigma_{A} \neq \bar{\sigma}_{A}}}\left[\widehat{E}_{t}^{A, \sigma_{A} \rightarrow \bar{\sigma}_{A}, w}\left(y_{t}^{l}\right)+\widehat{E}_{t}^{A, \sigma_{A} \rightarrow \bar{\sigma}_{A}, \widehat{w}}\left(y_{t}^{l}+\Delta^{l}\right)\right] .
$$

em que $y_{t}^{l}$ é a trajetória do perfil de densidade no nível $l$.

A construção feita na $l$-ésima etapa faz sentido, e as suas taxas são corretas, para $t \geq \tau_{l}$. Portanto, junto com a construção gráfica assumida para $t \in\left[0, \tau_{l}\right)$, esta define corretamente o acoplamento para $\mathrm{g}_{t}^{x^{0}, N}$ e $\widehat{\mathrm{g}}_{t}^{B\left(x^{0}\right), N}$ no tempo todo. Porém, tal acoplamento (no nível $l$ ) perde precisão após a seguinte discrepância acontecer, então declinamos desta para $t \geq \tau_{l+1}$, e vamos substituí-lo 
pela construção no nível $(l+1)$ correspondente à $(l+1)$-ésima etapa. Nesta etapa começamos com $\mathrm{g}_{\tau_{l+1}, N}^{x^{0}}-\widehat{\mathrm{g}}_{\tau_{l+1}}^{B\left(x^{0}\right), N}=\Delta^{l+1}, \operatorname{com}\left|\Delta^{l+1}-\Delta^{l}\right|=\frac{2|A|}{N}$, para algum $A \in \mathcal{P}^{*}(\mathcal{T})$.

Esta construção recursiva é continuada, para cada trajetória, até o tempo $t=N T$ ser atingido. Como veremos logo, dado que as taxas são limitadas superiormente, o procedimento envolve, quase certamente, um número finito de etapas. O processo

$$
\bar{D}_{t}=D_{t}^{l} \text { se } t \in\left(\tau_{l}, \tau_{l+1}\right]
$$

$l=0,1 \ldots\left(\tau_{0}=0\right)$, conta o número de discrepâncias. Este satisfaz a relação $\left\{\bar{D}_{t} \geq l\right\}=\left\{\tau_{l} \leq t\right\}$.

\subsubsection{Controle do processo de discrepância}

Denotando $\bar{D}_{N t}$ o número de discrepâncias entre os processos de perfil de densidade. Lembramos que $|A| \leq k, \forall A \in \mathcal{P}^{*}(\mathcal{T})$. Logo, em concordância com (5.2) e o acima definido, podemos dizer que:

$$
\left|w_{t}^{x^{0}, N}-\widehat{w}_{t}^{B\left(x^{0}\right), N}\right| \leq \frac{2 k \bar{D}_{N t}+d}{N}
$$

Para estimar o lado direito, vamos propor um lema que entrega um majorante para as taxas dos processos $\left\{\bar{D}_{t}\right\}$.

Lema 5.1.2. Considere $N \in \mathbb{N}, T \geq 0$ e $\delta>0$. Para cada $l \in \mathbb{N}$, seja $R_{t}^{l}$ a taxa instantânea do nivel $l$ do processo de discrepância $D_{t}^{l}, t \in\left[\tau_{l}, \tau_{l+1}\right]$ definido anteriormente e seja $R^{l}=\sup \left\{R_{t}^{l}: t \in\right.$ $\left.\left[\tau_{l}, \tau_{l+1}\right] \cap[0, N T]\right\}$. Então existe uma constante $C>0$ tal que os eventos

$$
\mathcal{R}_{\delta}^{N T}=\left\{R^{l} \leq N^{\delta-1 / 2}+\frac{C l}{N}, \forall l \text { t.q } \tau_{l} \leq N T\right\}
$$

satisfazem,

$$
P\left(\underline{\lim }_{N} \mathcal{R}_{\delta}^{N T}\right)=1
$$

Demonstração. Seja $\Delta_{t}$ a distância entre as realizações geométricas acopladas $\mathrm{g}_{t}^{x^{0}, N}$ e $\widehat{\mathrm{g}}_{t}^{B\left(x^{0}\right), N}$ :

$$
\Delta_{t}=\sum_{l \geq 0} \Delta^{l} \mathbf{1}_{t \in\left[\tau_{l}, \tau_{l+1}\right)}
$$

Assim, vemos que o processo de discrepância pode ser escrito como

$$
\bar{D}_{t}=\sum_{A \in \mathcal{P}^{*}(\mathcal{T})} \sum_{\substack{\sigma_{A}, \bar{\sigma}_{A} \in \mathcal{S}_{A} \\ \sigma_{A} \neq \bar{\sigma}_{A}}}\left[\widehat{E}_{t}^{A, \sigma_{A} \rightarrow \bar{\sigma}_{A}, w}\left(\mathrm{~g}_{t}^{x^{0}, N}\right)+\widehat{E}_{t}^{A, \sigma_{A} \rightarrow \bar{\sigma}_{A}, \widehat{w}}\left(\mathrm{~g}_{t}^{x^{0}, N}+\Delta_{t}\right)\right] .
$$


Dizemos que $R_{t}$ representa a taxa associada ao processo $\bar{D}_{t}$. Usando (5.15) com a seguinte propriedade do mínimo

$$
\min \{a, b\}=\frac{|a+b|-|a-b|}{2}
$$

obtemos

$R_{t}=\sum_{A \in \mathcal{P}^{*}(\mathcal{T})} \sum_{\substack{\sigma_{A}, \bar{\sigma}_{A} \in \mathcal{S}_{A} \\ \sigma_{A} \neq \bar{\sigma}_{A}}}\left|\left(\mathrm{~g}_{t}^{x^{0}, N}\right)_{\left(A, \sigma_{A}\right)} \lambda_{A}^{\sigma_{A} \rightarrow \bar{\sigma}_{A}}\left(\mathrm{~g}_{t}^{x^{0}, N}\right)-\left(\left(\mathrm{g}_{t}^{x^{0}, N}\right)_{\left(A, \sigma_{A}\right)}+\left(\Delta_{t}\right)_{\left(A, \sigma_{A}\right)}\right) \lambda_{A}^{\sigma_{A} \rightarrow \bar{\sigma}_{A}}\left(x_{t / N}^{x^{0}}\right)\right|$.

Esta última é uma soma de um número finito de elementos; além disso, por definição $0 \leq\left(\mathrm{g}_{t}^{x^{0}, N}\right)_{\left(A, \sigma_{A}\right)} \leq 1,0 \leq\left(\mathrm{g}_{t}^{x^{0}, N}\right)_{\left(A, \sigma_{A}\right)}+\left(\Delta_{t}\right)_{\left(A, \sigma_{A}\right)} \leq 1$. Logo, obtemos uma constante $K$ tal que

$$
R_{t} \leq K\left|\lambda_{A}^{\sigma_{A} \rightarrow \bar{\sigma}_{A}}\left(\mathrm{~g}_{t}^{x^{0}, N}\right)-\lambda_{A}^{\sigma_{A} \rightarrow \bar{\sigma}_{A}}\left(x_{t / N}^{x^{0}}\right)\right|
$$

Devido à condição de Lipschitz (4.9), a diferença tem um crescimento no máximo linear e existe uma constante $C$ tal que a taxa $R_{t}$ é limitada superiormente.

$$
R_{t} \leq C\left|\mathrm{~g}_{t}^{x^{0}, N}-x_{t / N}^{x^{0}}\right|
$$

Usando desigualdade triangular, introduzimos o processo $\widehat{\mathrm{g}}_{t}^{B\left(x^{0}\right), N}$ e dizemos que:

$$
R_{t} \leq C\left|\widehat{\mathrm{g}}_{t}^{B\left(x^{0}\right), N}-x_{t / N}^{x^{0}}\right|+C\left|\mathrm{~g}_{t}^{x^{0}, N}-\widehat{\mathrm{g}}_{t}^{B\left(x^{0}\right), N}\right|
$$

Dada uma realização da construção gráfica, o segundo termo é limitado superiormente.

$$
\left|\mathrm{g}_{t}^{x^{0}, N}-\widehat{\mathrm{g}}_{t}^{B\left(x^{0}\right), N}\right| \leq \frac{2 k l}{N}+\left|\widehat{\mathrm{g}}_{0}^{B\left(x^{0}\right), N}-x^{0}\right| \text { se } t \in\left[\tau_{l}, \tau_{l+1}\right)
$$

Para o primeiro termo em (5.26) e a segunda parte de (5.27), vamos aplicar um limitante probabilístico:

$$
\begin{aligned}
P\left(\left|\widehat{\mathrm{g}}_{t}^{B\left(x^{0}\right), N}-x_{t / N}^{x^{0}}\right|>\frac{1}{2 C} N^{\delta-1 / 2}\right) & =P\left(\left|\widehat{\mathrm{g}}_{0}^{B\left(x^{0}\right), N}-x^{0}\right|>\frac{1}{2 C} N^{\delta-1 / 2}\right) \\
& =P\left(\left|\widehat{w}_{t / N}^{B\left(x^{0}\right), N}-x_{t / N}^{x^{0}}\right|>\frac{1}{2 C} N^{\delta-1 / 2}\right) \\
& <\exp \left(-c N^{\delta}\right),
\end{aligned}
$$

valido para cada $t \geq 0$. Agora precisamos um limitante $\forall t \in[0, N T]$. Considerando $\gamma>0$ e $M$ como 
sendo a parte inteira de $N^{\gamma}$. Para cada $0 \leq j \leq M$, definimos

$$
C_{j}=\left\{\left|\widehat{\mathrm{g}}_{j N T / M}^{B\left(x^{0}\right), N}-x_{j T / M}^{x^{0}}\right| \leq \frac{1}{2} N^{\delta-1 / 2}\right\},
$$

este evento diz que a distancia entre os processos $\widehat{w}_{t}^{B\left(x^{0}\right), N}$ e $x_{t}^{x^{0}}$, em um instante fixo $j T / M \in[0, T]$, é menor ou igual a $\frac{1}{2} N^{\delta-1 / 2}$. Seja também

$$
\Theta=\inf \left\{t \geq 0:\left|\widehat{\mathrm{g}}_{t}^{B\left(x^{0}\right), N}-x_{t / N}^{x^{0}}\right|>\frac{1}{2} N^{\delta-1 / 2}\right\}
$$

Então,

$$
\begin{aligned}
P(\Theta \leq N T) & =P\left(\Theta \leq N T, \cap_{l=0}^{M} C_{l}\right)+P\left(\Theta \leq N T, \cup_{l=0}^{M} C_{l}^{c}\right) \\
& \leq P\left(\Theta \leq N T, \cap_{l=0}^{M} C_{l}\right)+\sum_{l=0}^{M}\left(1-P\left(C_{l}\right)\right) \\
& \leq M\left[1-\left(1+\frac{d N T}{M}\right) \exp (-d N T / M)\right]+M \exp \left(-c N^{\delta}\right) \\
& \leq c N^{2-\gamma},
\end{aligned}
$$

em que $d$ e $c$ são constantes positivas. Na terceira linha usamos (5.28) para limitar o último termo; para o outro termo, é possivel olhar que as condições $\Theta \leq N T$ e $\cap_{l=0}^{M} C_{l}$ juntas implicam que o processo teria que ter, no mínimo, duas transições no intervalo de tempo de tamanho $N T / M$ que contem $\Theta$. A constante $d$ limita as taxas do processo $\left\{\widehat{\mathrm{g}}_{t}^{B\left(x^{0}\right), N}\right\}_{t \geq 0}$ (poderiamos pegar $d=$ $\left.\sum_{A \in \mathcal{P}^{*}(\mathcal{T})} \sum_{\sigma_{A}, \bar{\sigma}_{A} \in \mathcal{S}_{A}}\left\|\lambda_{A}^{\sigma_{A} \rightarrow \bar{\sigma}_{A}}\right\|_{\infty}\right)$. A escolha de $\gamma>3$ permite a convergência do majorante em (5.31), que implica.

$$
P\left(\varlimsup_{N}\{\Theta \leq N T\}\right)=0 .
$$

Este resultado junto com (5.27) provam (5.20).

Para finalizar a prova do Teorema 4.2.1 vamos incluir um lema que controla a quantidade de discrepâncias que acontecem no nosso acoplamento.

Lema 5.1.3. Para qualquer $\varepsilon>0$, e $0 \leq t \leq T$,

$$
P\left(\varlimsup_{\overline{\lim }}\left\{\bar{D}_{N T} \geq N^{\varepsilon+1 / 2}\right\}\right)=0
$$

Demonstração. Definindo $\widetilde{N}_{t}=\bar{D}_{N t}$. Lembramos que este processo conta o número de discrepâncias na escala de tempo de $\left\{w_{t}^{x^{0}, N}\right\}_{t \geq 0}$. Portanto, possui taxas $N$ vezes maiores que as do processo $\bar{D}_{t}$. 
Seja $\mathbf{T}_{N}$ o tempo necessário para atingir as $N^{\varepsilon+1 / 2}$ discrepâncias.

$$
\mathbf{T}_{N}=\min \left\{t: \widetilde{N}_{t} \geq N^{\varepsilon+1 / 2}\right\}
$$

Este pode ser escrito como

$$
\mathbf{T}_{N}=\sum_{i=1}^{N_{+}^{\varepsilon+1 / 2}} T_{i}
$$

com $T_{1}, T_{2}, \ldots$ os independentes tempos sucessivos esperados entre cada salto e $N_{+}^{\varepsilon+1 / 2}$ sendo o menor inteiro maior ou igual a $N^{\varepsilon+1 / 2}$.

Agora é escolhido $0<\delta<\varepsilon$. Do Lema 5.1.2, definimos os eventos

$$
\mathcal{D}_{r}=\{\text { condição }(5.19) \text { é valida para } N \geq r\}
$$

estes satisfazem,

$$
P\left(\bigcup_{r \in \mathbb{N}} \mathcal{D}_{r}\right)=1
$$

mas não representam necessariamente uma partição. Consequentemente

$$
P\left(\varlimsup_{N}\left\{\mathbf{T}_{N}<T\right\}\right) \leq \sum_{r} P\left(\varlimsup_{\lim }\left\{\mathbf{T}_{N}<T\right\}, \mathcal{D}_{r}\right)
$$

Se for possível verificar que a soma do lado direito é nula, completamos a prova do lema. Assim, baseado no lema Borel-Cantelli convertimos essa tarefa em demonstrar o seguinte resultado

$$
\sum_{N} P\left(\mathbf{T}_{N}<T, \mathcal{D}_{r}\right)<\infty
$$

para cada $r \in \mathbb{N}$. Para prová-lo vamos somar, de uma outra maneira, a decomposição (5.35) em blocos dados por

$$
Q=\frac{N_{+}^{\varepsilon+1 / 2}}{N_{+}^{\delta+1 / 2}} \sim N^{\varepsilon-\delta} \stackrel{N \rightarrow \infty}{\longrightarrow} \infty
$$

Considerando $I_{l}=\left[(l-1) N_{+}^{\delta+1 / 2}+1, l N_{+}^{\delta+1 / 2}\right]$ e escrevendo,

$$
\mathbf{T}_{N}=\sum_{l=1}^{Q} G_{l}, \quad G_{l}=\sum_{j \in I_{l}} T_{j}
$$


Sob $\mathcal{D}_{r}$ o processo $\left\{\widetilde{N}_{t}\right\}_{t \geq 0}$ pula de $i$ para $i+1$ com taxas majoradas por $N^{\delta+1 / 2}+C i$. Isto é, para cada $i \in I_{l}$ a taxa de $T_{i}$ é superiormente limitada por $N^{\delta+1 / 2}+C l N_{+}^{\delta+1 / 2}$, que é menor que $(C l+1) N_{+}^{\delta+1 / 2}$ se $N$ é o suficientemente grande. Isto prova que, para tais $N$, a saída de cada variável $G_{l}$ é menor que o valor da soma de $N_{+}^{\delta+1 / 2}$ variáveis exponenciais i.i.d. com taxa $(C l+1) N_{+}^{\delta+1 / 2}$. Portanto

$$
P\left(\mathbf{T}_{N}<T, \mathcal{D}_{r}\right) \leq P\left(\sum_{l=1}^{Q} \frac{G_{l}\left(N_{+}^{\delta+1 / 2}\right)}{(C l+1) N_{+}^{\delta+1 / 2}}<T\right)
$$

em que $\left\{G_{l}\left(N_{+}^{\delta+1 / 2}\right)\right\}_{l \geq 1}$ denota uma sequência de variáveis aleatórias i.i.d. com distribuição gama com parâmetros $n=N_{+}^{\delta+1 / 2}$ e $\lambda=1$. As propriedades de grandes desvíos para esta distribuição implicam que cada variável $G_{l, N}=G_{l}\left(N_{+}^{\delta+1 / 2}\right) / N_{+}^{\delta+1 / 2}$ satisfaz,

$$
P\left(G_{l, N}<1 / 2\right) \leq \exp \left(-c N^{\delta+1 / 2}\right),
$$

para alguma constante $c>0$, todo $1 \leq l \leq Q$ e $N$ suficientemente grande. Além disso, denotando $A_{l, N}=\left\{G_{l, N} \geq 1 / 2\right\} \cap \mathcal{D}_{r}$ e $B_{Q, N}=\cap_{l=1}^{Q} A_{l, N} \cap \mathcal{D}_{r}$ temos que,

$$
\begin{aligned}
P\left(\mathbf{T}_{N}<T, \mathcal{D}_{r}\right) & =P\left(\mathbf{T}_{N}<T, \mathcal{D}_{r}, B_{Q, N}^{c}\right)+P\left(\mathbf{T}_{N}<T, \mathcal{D}_{r}, B_{Q, N}\right) \\
& \leq P\left(\cup_{l=1}^{Q}\left\{G_{l, N}<1 / 2\right\}\right)+P\left(\mathbf{T}_{N}<T, B_{Q, N}\right)
\end{aligned}
$$

Sob o evento $B_{Q, N}, \mathbf{T}_{N}$ é limitado inferiormente por

$$
\frac{1}{2} \sum_{l=1}^{Q} \frac{1}{C l+1} \sim \log Q \stackrel{N \rightarrow \infty}{\longrightarrow} \infty
$$

Assim, o segundo termo do majorante de (5.44) é zero para $N$ suficientemente grande. Limitando o primeiro termo pela estimativa de grandes desvíos dada em (5.43) concluímos que,

$$
P\left(\mathbf{T}_{N}<T, \mathcal{D}_{r}\right) \leq Q \exp \left(-c N^{\delta+1 / 2}\right)
$$

para $N$ suficientemente grande. Dado que a última expressão é somável, podemos provar (5.39).

\subsection{Prova dos resultados das análises de bifurcações}

A seguir apresentamos as demonstrações dos resultados enunciados na Seção 4.3. Devido à natureza não linear dos sistemas dinâmicos, a estabilidade dos pontos de equilíbrio é analisada 
utilizando a ferramenta de linearização em torno de um ponto fixo. Particularmente examinamos os autovalores da matriz associada.

\subsubsection{Prova do Teorema 4.3.1}

Considerando o sistema de equações diferenciais:

$$
\dot{x}_{i}=e^{s_{a(i)} J\left(x_{a(i)}-\frac{1}{2}\right)}-x_{i}\left(e^{s_{a(i)} J\left(x_{a(i)}-\frac{1}{2}\right)}+e^{-s_{a(i)} J\left(x_{a(i)}-\frac{1}{2}\right)}\right)
$$

para $1 \leq i \leq k$. Aplicando o método de linearização em torno ao ponto $\mathbf{1} / \mathbf{2}=(1 / 2, \ldots, 1 / 2) \in \mathbb{R}^{k}$, obtemos a matriz

$$
\mathbf{A}=\left(\begin{array}{ccccc}
-2 & 0 & \ldots & 0 & s_{k} J \\
s_{1} J & -2 & \ldots & 0 & 0 \\
\vdots & \vdots & \ddots & \vdots & \vdots \\
0 & 0 & \ldots & s_{k-1} J & -2
\end{array}\right)
$$

Portanto o sistema dinâmico linear associado é dado por

$$
\dot{x}_{i}=-2\left(x_{i}-1 / 2\right)+s_{a(i)} J\left(x_{a(i)}-1 / 2\right)
$$

Como foi dito, é preciso a análise dos autovalores, os quais são achados ao resolver $\operatorname{det}[\lambda I-A]=0$. Assim, obtemos a equação seguinte

$$
(\lambda+2)^{k}+J^{k} \prod_{i=1}^{k} s_{i}=0
$$

Sendo $s=\prod_{i=1}^{k} s_{i}$. Podemos achar as soluções

$$
s J e^{\frac{2 \pi l}{k} i}-2, \quad l=0,1, \ldots, k-1 .
$$

Logo, quando $s=1$, o ponto fixo $\mathbf{1} / \mathbf{2}$ perde estabilidade em $J_{c}=2$ quando o autovalor correspondente a $l=0$ atravessa o eixo imaginário através da origem. No outro caso, se $s=-1$, a estabilidade é perdida quando dois autovalores, simétricos em torno ao eixo real, cruzam o eixo imaginário. Isto acontece em $J_{c}=\frac{2}{\cos (\pi / k)}$.

\subsubsection{Prova da Proposição 4.3.2}

a) Para $s_{i}=1, \forall i \in \mathcal{T}$ e $h_{i}=-J / 2$ : o sistema dinâmico em (4.13) tem como ponto de equilíbrio $\left(\frac{1}{2}, \frac{1}{2}, \frac{1}{2}\right)$. Deste modo, aplicando a técnica de linearização a matriz associada é 


$$
\mathbf{A}=\left(\begin{array}{ccc}
-2 & (1-\delta) J & \delta J \\
\delta J & -2 & (1-\delta) J \\
(1-\delta) J & \delta J & -2
\end{array}\right)
$$

Com o software Maxima [19], obtemos os autovalores

$$
\begin{gathered}
\lambda_{1}=J-2 \\
\lambda_{2}=-\frac{(2 \sqrt{3} i \delta-\sqrt{3} i+1) J+4}{2} \\
\lambda_{3}=\frac{(2 \sqrt{3} i \delta-\sqrt{3} i-1) J-4}{2}
\end{gathered}
$$

Vemos que o ponto fixo perde estabilidade com $J_{c}=2$, quando o autovalor puramente real, atravessa o eixo imaginario na origem. Nesse momento aparecem dois pontos fixos estáveis, como mostra a Figura 4.2 .

b) No caso $s_{i}=-1, \forall i \in \mathcal{T}$ e $h_{i}=J / 2$ : o sistema associado a (4.13) apresenta um ponto fixo em $\left(\frac{1}{2}, \frac{1}{2}, \frac{1}{2}\right)$. De modo que a matriz $A$ referente é definida por

$$
\mathbf{A}=\left(\begin{array}{ccc}
-2 & -(1-\delta) J & -\delta J \\
-\delta J & -2 & -(1-\delta) J \\
-(1-\delta) J & -\delta J & -2
\end{array}\right)
$$

Finalmente, obtemos os autovalores com o software Maxima [19],

$$
\begin{gathered}
\lambda_{1}=-J-2 \\
\lambda_{2}=-\frac{(2 \sqrt{3} i \delta-\sqrt{3} i-1) J+4}{2} \\
\lambda_{3}=\frac{(2 \sqrt{3} i \delta-\sqrt{3} i+1) J-4}{2}
\end{gathered}
$$

Assim, podemos ver que o ponto fixo perde estabilidade com $J_{c}=4$, quando os autovalores $\lambda_{1}$ e $\lambda_{2}$ (simétricos em torno ao eixo real), atravessam o eixo imaginário. Para $J>4$ aparece uma bifurcação de tipo Hopf, como apresentamos na Figura 4.3. 


\section{Referências Bibliográficas}

[1] A. Anderson, M. Chaplain, K.A. Rejniak (Editores), Single-Cell-Based Models in Biology and Medicine. Mathematics and Biosciences in Interaction. Birkhäuser Verlag, Basel, 2007.

[2] N. Britton, Essential Mathematical Biology. Springer, New York, 2003.

[3] R. Cheong, A. Hoffmann, A. Levchenko, Understanding NF- $\kappa B$ signaling via mathematical modeling. Molecular Systems Biology (2008) 4:192.

[4] L. Chong, L.B. Ray, Whole-istic Biology. Science (2002) 295: 1661.

[5] F. den Hollander, Large Deviations. Fields Institute Monographs, vol 14. American Mathematical Society, Providence, 2000.

[6] R. Durrett, Stochastic Spatial Models. SIAM Rev. (1999) 41(4): 677-718.

[7] B. Ermentrout, J. Rinzel, XPPAUT: X-Windows PhasePlane plus Auto. http://www.math.pitt.edu/ bard/xpp/xpp.html.

[8] S.N. Ethier, T.G. Kurtz, Markov Processes, Characterization and Convergence. Wiley, New York, 1986.

[9] R. Fernandez, L.R. Fontes, E.J. Neves, Density-Profile Processes Describing Biological Signaling Networks: Almost Sure Convergence to Deterministic Trajectories. J Stat Phys (2009) 136: 875-901.

[10] J. Guckenheimer, P. Holmes, Nonlinear Oscillations, Dynamical Systems, and Bifurcations of Vector Fields. Applied Mathematical Sciences, 42. Springer-Verlag, Berlin, 1997.

[11] L.H. Hartwell, J.J. Hopfield, S. Leibler, A.W. Murray, From molecular to modular cell biology. Nature (1999) 402: C47-C52.

[12] A. Hoffmann, A. Levchenko, M.L. Scott, D. Baltimore, The I $\kappa-N F-\kappa B$ Signaling Module: Temporal Control and Selective Gene Activation. Science (2002) 298: 1241-1245.

[13] J. Keener, J. Sneyd, Mathematical Physiology. Springer, New York, 1998.

[14] S. Krishna, M.H. Jensen, K. Sneppen, Minimal model of spiky oscillations in NF- $\kappa B$ signaling. Proc. Natl. Acad. Sci. USA (2006) 103(29): 10840-10845. 
[15] G. Lahav, N. Rosenfeld, A. Sigal, N. Geva-Zatorsky, A.J. Levine, M.B. Elowitz, U. Alon, Dynamics of the p53-Mdm2 feedback loop in individual cells. Nat Genet. (2004) 36(2): 147150.

[16] T.M. Liggett, Interacting Particle Systems. Springer, Berlin, 1985.

[17] H. Lodish, A. Berk, Paul Matsudaira, C.A. Kaiser, M. Krieger, M.P. Scott, L. Zipursky, J. Darnell, Molecular Cell Biology. Fifth Edition. Freeman, New York, 2003.

[18] L. Ma, J. Wagner, J.J. Rice, W. Hu, A.J. Levine, G.A. Stolovitzky A plausible model for the digital response of $p 53$ to DNA damage. Proc. Natl. Acad. Sci. USA (2005) 102(40): 14266-14271.

[19] Maxima.sourceforge.net, Maxima, a Computer Algebra System. Version 5.18.1 (2010).

[20] G. Mirams, H. Byrne, J. King, A multiple timescale analysis of a mathematical model of the Wnt/ $\beta$-catenin signalling pathway. J. Math. Biol. (2010) 60: 131-160.

[21] J.D. Murray, Mathematical biology. I. An introduction. Springer, New York, 2005.

[22] K. Oda, Y. Matsuoka, A. Funahashi, H. Kitano, A comprehensive pathway map of epidermal growth factor receptor signaling. Molecular Systems Biology 1:2005.0010.

[23] L. Perko, Differential Equations and Dynamical Systems. Third Edition. Springer, New York, 2001.

[24] J.P. Qi, S.H. Shao, Jinli Xie, Y. Zhu, A mathematical model of P53 gene regulatory networks under radiotherapy. BioSystems (2007) 90: 698-706.

[25] L. Segel (Editor), Mathematical Models in Molecular and Cellular Biology. Cambridge University Press, New York, 1983.

[26] E.D. Sontag, Some new directions in control theory inspired by systems biology. Syst. Biol. (2004) 1: 9-18.

[27] S. Strogatz, Nonlinear dynamics and chaos: with applications to physics, biology, chemistry, and engineering. Perseus Books, Cambridge, 1994.

[28] D. Stroock, S.R.S. Varadhan, Multidimensional Diffusion Processes. Springer-Verlag, Berlin, 1979.

[29] H. Thorrison, Coupling, Stationarity and Regeneration. Probability and its Applications, First Edition. Springer, New York, 2001.

[30] J.J. Tyson, A. Csikasz-Nagy, B. Novak, The dynamics of cell cycle regulation. Bioessays (2002) 24(12): 1095-1109.

Manuel Alejandro González Navarrete 
[31] S. Wiggins, Introduction to Applied Nonlinear Dynamical Systems and Chaos. Springer-Verlag, New York, 1990.

[32] D.M. Wolf, A.P. Arkin, Motifs, modules and games in bacteria. Current Opinion in Microbiology (2003) 6(2): 125-134.

[33] F. Y. Wu, The Potts model. Rev. Mod. Phys. (1982) 54(1): 235-268.

[34] T. Zhang, P. Brazhnik, J.J. Tyson, Exploring mechanisms of the DNA-damage response: p53 pulses and their possible relevance to apoptosis. Cell Cycle (2007) 6(1): 85-94. 